\title{
Personal temporal en la Administración Pública: soluciones de presente y opciones de futuro
}

\section{Temporary employment in Public Administration: current solutions and future options}

\author{
Xavier Boltaina Bosch \\ Universitat Oberta de Catalunya (España) \\ ORCID: https://orcid.org/0000-0002-7650-6513 \\ xboltaina@uoc.edu
}

\begin{abstract}
NOTA BIOGRÁFICA
Doctor en Derecho (UAB). Doctor en Seguridad Internacional (IUGM-UNED). Directivo Público profesional de la Diputación de Barcelona y profesor de Derecho y Ciencia Política de la Universitat Oberta de Catalunya y profesor honorario de la Universidad Rovira Virgili. Ha ejercido la función docente universitaria desde 1994 en diferentes Universidades (UAB, UB y UOC). Las líneas de investigación desarrolladas son fundamentalmente el Derecho del Empleo Público y, en especial, el empleo público temporal. Puede consultarse una parte de sus publicaciones en: https://dialnet.unirioja.es/servlet/autor?codigo=83318.
\end{abstract}

\section{RESUMEN}

Este documento se ha concebido como una reflexión, forzosamente breve y en tiempo actual, de la situación del empleo público temporal, el itinerario histórico desde 1976 a 2020, la perspectiva a 20212022 y las opciones de futuro. En este sentido se analizan las razones por las cuáles se ha llegado a que el empleo temporal alcance tasas elevadísimas en la Administración española, el recorrido para intentar reducirlo a unos porcentajes admisibles durante 2021 y finalmente, las medidas que podrían plantearse a corto y medio plazo para evitar repetir los errores del pasado y del presente, para que en un periodo de cinco o diez años no vuelva a repetirse la situación actual.

\section{PALABRAS CLAVE}

Función pública; empleo temporal; funcionarios interinos; personal laboral temporal; trabajadores indefinidos no fijos; temporalidad; estabilización del empleo temporal.

\begin{abstract}
This document is devised as a reflection, necessarily brief, based on the current temporary public employment situation, using the historical itinerary from 1976 to 2020, the prospect of 2021-2022 and the future outcome. In this sense, the reasons because there are such high rates of temporary employment in the Spanish Administration are analysed along with the methods to try to reduce it to admissible percentages during 2021, and, finally, the measures that could be considered in the short and medium term to avoid repeating the mistakes of past and present time for the next five or ten years.
\end{abstract}

\section{KEYWORDS}

Public service; temporary employment; temporary civil servants; temporary work staff; permanent nonregular workers; impermanence; stabilisation of temporary employment. 
DA. Nueva Época - N. ${ }^{\circ}$, diciembre 2021 - ISSN: 1989-8983 - DOI: https://doi.org/10.24965/da.i8.11025 - [Págs. 66-91]

Personal temporal en la Administración Pública: soluciones de presente y opciones de futuro

Xavier Boltaina Bosch

\begin{abstract}
SUMARIO
CONSIDERACION PREVIA. 1. INTRODUCCIÓN: LA TEMPORALIDAD EN EL EMPLEO PÚBLICO COMO PROBLEMA ESTRUCTURAL E INSTITUCIONAL. 2. LA TEMPORALIDAD PÚBLICA Y EL ITINERARIO HISTÓRICO EN EL PERIODO DEMOCRÁTICO: DE LA «TRANSICIÓN» A LA APROBACIÓN DEL ESTATUTO BÁSICO DEL EMPLEADO PÚBLICO (1976-2007). 3. LA RESPUESTA DEL ESTATUTO BÁSICO DEL EMPLEADO PÚBLICO DE 2007 A LA TEMPORALIDAD. 4. LAS SOLUCIONES DEL «PRESENTE»: DEL EBEP AL 2021. 5. LA RESPUESTAS DEL REAL DECRETO-LEY 14/2021 Y LOS ACUERDOS PARLAMENTARIOS POSTERIORES: LOS ELEMENTOS CLAVES DE SOLUCIONES DE «MIRADA CORTA». 6. ¿LAS OPCIONES DE FUTURO?: RECONDUCIR LA TEMPORALIDAD Y LA SELECCIÓN DE PERSONAL PERMANENTE EN LAADMINISTRACIÓN PÚBLICA. $10^{\circ}$ RECONDUCIR LA FIGURA DE LA TEMPORALIDAD FUNCIONARIAL A SUS JUSTOS TÉRMINOS JUSTIFICATIVOS: FUNCIONARIOS CAUSALES. $2 .^{\circ}$ RESITUAR LA PRESENCIA DEL CONTRATO LABORAL TEMPORAL EN EL ÁMBITO DE LA ADMINISTRACIÓN Y CONCRETAR EL MODELO SELECTIVO Y LA DURACIÓN DEL CONTRATO TEMPORAL. 3. ${ }^{\circ}$ EL FORTALECIMIENTO DE LAS BASES DE LAS CONVOCATORIAS, LOS REQUISITOS EXIGIBLES, EL PROCESO SELECTIVO Y EL PAPEL TRIBUNALES DE SELECCIÓN DE PERSONAL TEMPORAL E INTERINO. 4. ${ }^{\circ}$ SUPRIMIR O RECONDUCIR LA «TASA DE REPOSICIÓN DE EFECTIVOS». 5. ${ }^{\circ}$ LA OBLIGATORIEDAD DE LA CONVOCATORIA DE LAS OFERTAS DE EMPLEO PÚBLICO EN LOS TÉRMINOS QUE ANUALMENTE FIJE LA LEGISLACIÓN APLICABLE. 6. ${ }^{\circ}$ LA REGULACIÓN JURÍDICA DE LA FIGURA DEL «TRABAJADOR INDEFINIDO NO FIJO». LA INTERDICCIÓN DE CREACIÓN JUDICIAL DE NUEVAS FIGURAS DE EMPLEADOS PÚBLICOS EN EL ÁMBITO FUNCIONARIAL INTERINO. 7. ${ }^{\circ}$ LA EXIGENCIA DE RESPONSABILIDADES POR LOS INCUMPLIMIENTOS EN LA CONTRATACIÓN LABORAL TEMPORAL Y EL FUNCIONARIADO INTERINO. 8. ${ }^{\circ}$ LA REGULACIÓN DE LAS «BOLSAS DE TRABAJO» O SU PLAUSIBLE SUPRESIÓN. 9. ${ }^{\circ}$ SUPERAR LOS DESIDERÁTUMS PORCENTUALES: EL 8 POR CIENTO DE LA LEY 6/2018 Y NORMAS POSTERIORES. 10. ${ }^{\circ}$ LA REFORMULACIÓN AL SIGLO XXI DE LOS CONCEPTOS DE «IGUALDAD», «MÉRITO» Y «CAPACIDAD». REFERENCIAS BIBLIOGRÁFICAS.
\end{abstract}

\title{
CONSIDERACION PREVIA
}

El inicio de redacción de este documento, por encargo de la revista Documentación Administrativa fue en octubre de 2021. Desde julio de 2021, con la promulgación del RD-ley 14/2021 sobre reducción de la temporalidad en la Administración Pública, esta cuestión ha estado permanentemente en el candelero del debate social y jurídico, que ya arrastraba años de debate político, jurídico y sindical.

La dificultosa convalidación del RD-ley 14/2021, la posterior tramitación como Ley y el hecho de que al cierre de redacción de este documento, no haya todavía una Ley aprobada, sino que se encuentre en el trámite de enmiendas y aprobación por el Congreso previo pase al Senado, supone que algunas de las consideraciones que se efectúan a lo largo del documento puedan quedar desactualizadas cuando vea la luz ${ }^{1}$, si bien los elementos esenciales del mismo consideramos permanecerán vigentes por su carácter casi «intemporal». En todo caso, solicitamos disculpas si algunos elementos puedan ser contradictorios o diferentes a lo que finalmente resulte la Ley definitiva, que será aprobada por el Congreso -en trámite finalprevisiblemente en diciembre.

\section{INTRODUCCIÓN: LA TEMPORALIDAD EN EL EMPLEO PÚBLICO COMO PROBLEMA ESTRUCTURAL E INSTITUCIONAL}

La problemática del empleo temporal en la Administración Pública española se arrastra desde hace ya décadas e, incluso, podemos remontarnos al inicio mismo del siglo XX, calificado como una «historia interminable» por la doctrina más solvente en el ámbito del empleo público (Sánchez Morón, 2020, pp. 135-142). Un problema enquistado y que en el actual periodo democrático se ha ido incrementando a partir de 1975 y en especial desde 1978 hasta llegar a las cifras del 2021, que oscilan según las fuentes, entre 640 y 900 mil empleados temporales ${ }^{2}$, sobre un conjunto de empleo público que se sitúa entre los 2,7 y los 3,2 millones de empleados públicos, según sea la fuente estadística que tomemos como referencia ${ }^{3}$.

\footnotetext{
1 Hemos cerrado la redacción de este documento el 27 de noviembre de 2021.

2 El profesor Jiménez Asensio (2021) se hace eco de que incluso pueden ser 800 mil personas las afectadas, lo que de ser cierto supondría el 25 por ciento del total del empleo público de España, computando el sector público institucional.

3 Según los datos del Ministerio de Hacienda y Función Pública, a fecha de 1-1-2021, el personal al servicio de las Administraciones Públicas sumaba un total de 2,7 millones. Sin embargo, ya en 2016, el Instituto Nacional de Estadística a través de la Encuesta
} 
Se hace imprescindible, por ello, ubicar la cuestión en un marco histórico más reciente, que permita comprender la realidad al inicio de la tercera década del presente siglo XXI, para contextualizar la soluciones del "presente» así como las hipotéticas opciones "de futuro», aunque este futurible sea a corto y medio plazo y no sea ni tan siquiera ambicioso, sino posibilista.

A nuestro juicio, la temporalidad en la Administración es ya, en el 2021, «una cuestión de Estado», a la que debe hacerse frente y resolver, pese a los intentos reiterados en el pasado para lograrlo. "Cuestión de Estado», un concepto indeterminado, pero que podríamos definir como una situación lo suficientemente grave y duradera que afecta a la estabilidad de las instituciones públicas y sobre la que hay que tomar decisiones para las cuales no hay, o no sirven, los canales o formas habituales de decisión.

En este sentido, se ha comentado a menudo que la inmigración irregular masiva, la pandemia de la COVID-19, la crisis bancaria de a partir del 2010, entre otras., eran «cuestiones de Estado» en la medida que ponían -o siguen poniendo- en riesgo la estabilidad de ese Estado. Otras «cuestiones de Estado» van unidas no tanto a una emergencia, sino a la propia estabilidad presente y futura de las instituciones y de la vida de la ciudadanía: la seguridad pública, la enseñanza, el mantenimiento del sistema de pensiones o la sanidad universal son también -entre otras- cuestiones que merecen tal calificación y que los profesores Cantero y Jiménez Asensio (2021) califiquen de auténtico «problema institucional» (...) enquistado en el empleo público».

En este caso, hemos apostado siempre por interpretar que los niveles de temporalidad de la Administración ponen en cuestión el funcionamiento, ya no sólo regular, sino también efectivo, eficaz y coherente de un Estado moderno (Boltaina, 2005 y 2021).

Con la temporalidad excesiva no quebrará el Estado, no se pone en riesgo al propio Estado e incluso se podría convivir con ella ad aeternum, pero sí pueden quebrar valores muy profundos del sistema institucional (informe SAF, 2021), dado que la existencia de cientos de miles de empleados temporales encargados de prestar servicios públicos - muchos de ellos esenciales, como la sanidad y la educación- afecta a este funcionamiento del Estado Social y Democrático de Derecho, impiden aprobar políticas de función pública efectivas y plantear políticas de futuro y cronifican un problema subjetivo -los empleados afectados- transformándolo en un problema estructural que centra esfuerzos, energías y hasta el momento, ausencia de soluciones, que puede definirse como un «problema enquistado en el sector público por una mezcla de irresponsabilidad política, falta de capacidad de gestión e indolencia absoluta hacia los problemas de la profesionalización de la función pública» (Jiménez Asensio, 2021).

Cuestión también relevante es que las soluciones al problema -las del RD-ley 14/2021 y la posterior ley que se tramita en el Parlamento- suponga tal nivel de desatino y ruptura con los principios de igualdad, mérito y capacidad que, como han señalado algunos autores -y que compartimos- se «consolida el modelo de colonización política del empleo público que nos aqueja desde hace décadas. Un serio ataque a los principios constitucionales de igualdad, mérito y capacidad $\aleph^{4}$ o como acredita el informe del Sindicato Andaluz de Funcionarios (SAF, 2021), en su escrito de oposición al contenido de la nueva Ley.

En este sentido, a lo largo del presente documento, bajo el término de empleo «temporal» incluimos a todo el personal no permanente de las Administraciones y de su sector público, con una única excepción -el personal eventual de confianza o asesoramiento especial-. Así, nos referimos al personal funcionario o estatutario interino, el personal laboral temporal y el personal laboral indefinido no fijo e incluso figuras de creación judicial ajenas a la normativa, como la del «funcionario interino indefinido no fijo» de algunos juzgados contencioso-administrativos.

No incluimos, como hemos señalado, al personal eventual de confianza o asesoramiento especial, pues por propia definición es «temporal» al darse su nombramiento y cese por razones estrictamente políticos y, por consiguiente, su naturaleza es contrapuesta a una hipotética estabilidad futura, cuanto menos en la teoría jurídica y política, pese a que no en pocas ocasiones, estos nombramientos devienen en un paso previo a la condición de funcionario interino o personal temporal, cuando no empleados permanentes, al ubicarse en los centros de la palanca del poder y por tanto, poder usar su posición de prevalencia, para lograr fines a menudo poco acordes con la ética y la honestidad.

de Población Activa (EPA) situaba el número de empleados en 3,1 millones. Estos mismos datos se hacían constar en el documento del prof. Carles Ramió en "El envejecimiento de los empleados públicos", en El Blog de Espublico, 18-9-2017.

4 Francisco Longo, tuit de 12-11-2021, comentando el primer acuerdo en la Comisión del Congreso de 11-11-2021. 


\section{LA TEMPORALIDAD PÚBLICA Y EL ITINERARIO HISTÓRICO EN EL PERIODO DEMOCRÁTICO: DE LA «TRANSICIÓN» A LA APROBACIÓN DEL ESTATUTO BÁSICO DEL EMPLEADO PÚBLICO (1976-2007)}

La problemática de la temporalidad en el empleo público durante la presente etapa democrática, aunque hunde sus raíces en la historia, se acrecienta progresivamente a partir de 1976, vinculado generalmente a la construcción de las funciones públicas autonómicas y la expansión de los servicios que prestan las entidades locales, como Ayuntamientos y Diputaciones y, en general, la reordenación de todo el Estado, en proceso de «transición» democrática iniciada en el año 1976.

Este itinerario creemos que puede dividirse en dos periodos: el que se inicia en 1976 y se prolonga hasta la aprobación del Estatuto Básico del Empleado Público (EBEP) de 2007, que adoptó diversas medidas para reconducir el problema, si bien ha concluido en un parcial fracaso. Y a partir de esa fecha, una secunda secuencia que se inicia en 2007 y llega al 2022, un periodo de quince años con medidas contradictorias en un contexto político, económico y social extraordinariamente complejo y, además, con una fuerte influencia de la doctrina con origen en el Tribunal de Justicia de la Unión Europea, que en gran medida cristaliza en el RD-ley 14/2021 de 6 de julio y el posterior trámite parlamentario, que al cierre de este documento seguía en el Congreso de los Diputados.

Al respecto, creemos oportuno tratar diversos elementos que han coadyuvado, para bien y para mal, en este primer itinerario temporal que cubre el periodo 1976-2007.

Como hemos indicado, el personal temporal en la Administración Pública española es un problema estructural e institucional profundo, que hunde sus raíces casi al inicio mismo del sistema democrático en 1976, y aún más atrás en el tiempo, si tomamos una perspectiva histórica. En la práctica real, todos los gobiernos españoles de la etapa democrática han fracasado -total o parcialmente- en su voluntad de reducir o reconducir los porcentajes de temporalidad del empleo público, aunque también -dicho sea de paso- en el sector privado. España se ha convertido, así, en el top decem de la Unión Europea -cuanto menos, de la Europa previa a la ampliación hacia los países del Este de Europa- en cuanto a la temporalidad pública y privada. Como hemos señalado, la temporalidad en el empleo público es una «cuestión de Estado», aunque no ya de este momento, sino de las últimas décadas (Boltaina, 2021).

De hecho, durante la dictadura franquista, con la Ley de Funcionarios Civiles del Estado de 1964 se incorporó por vez primera una regulación específica de los «funcionarios interinos» y se preveía la contratación administrativa temporal para trabajos específicos, extraordinarios y urgentes, fórmula «rápida» y «discrecional» que permitió el recurso no sólo arbitrario sino también discriminatorio en el acceso al empleo público en el franquismo y en el periodo de transición democrática, tal como expone López Ramón (2021, p. 372). Pero nada es nuevo bajo el sol del empleo público español, como acredita la sentencia del Tribunal Supremo de 22 de abril de 1935 ya afirmó que «la exagerada permanencia» del funcionario interino en su cargo no "generaba derechos de propiedad (...) más bien constituiría materia de infracción administrativa», una afirmación que podría trasladarse miméticamente al 2022.

Las razones de este pandemónium no son únicas; unas pueden calificarse de formalistas, otras de sustanciales o de fondo, y también entremezcladas unas y otras. La temporalidad, más que una forma de gestión del empleo público se ha trasladado a ser una forma de acceso, una especie de «periodo de prueba» que puede prolongarse incluso décadas, previo al proceso selectivo para obtener la plaza permanente como funcionario o trabajador.

Elementos sustanciales, sin duda, fueron las que se basaron en la construcción de un nuevo Estado democrático; las Comunidades Autónomas no existentes durante la dictadura franquista y las entidades locales a partir de 1979 que ampliaron sus funciones -de iure y de facto-, estas últimas para cubrir las carencias del Estado (López Ramón, 2021, p. 373), comportaron la incorporación de cientos de miles de empleados en situación de «transitoriedad» e «inseguridad», que sólo a partir de la Ley 30/1984 de 2 de agosto de reforma de la función pública ${ }^{5}$ pudo iniciar un relativo enderezamiento.

Fue la época de contratos laborales temporales, contratos administrativos, funcionarios interinos sin apenas soporte legal por ausencia de leyes autonómicas y muchos más supuestos que supusieron una ingente cantidad de empleados que sólo a partir de 1984 pudieron normalizar sus respectivas situaciones. En

5 La Ley 30/1984 de 2 de agosto fue la primera ley de reforma de la función pública del también primer gobierno del presidente Felipe González. La Ley 30/1984, nacida como una norma transitoria, permanece aún vigente en algunos de sus preceptos, pese a la promulgación en el 2007 del EBEP. 
el ámbito local, decenas de miles de contratados laborales temporales pasaban a ser fijos posteriormente sin más trámite y sin cuestionar si ello ya colisionaba con el art.14 y 23.2 y 103 de la Constitución de 1978. En este sentido, creemos constatar un periodo entre 1978 y 1984 que se inserta en una «zona gris», por ausencia de desarrollo normativo de los referidos principios constitucionales, que sólo encaró el primer gobierno socialista en 1984, con la referida Ley 30/1984 y que dio paso a un mayor rigor, con la institucionalización de figuras tales como la «Oferta de Empleo Público» o determinados criterios de convocatoria y ejecución de esta Oferta.

Más «formales» -aunque sin evitar tener una justificación sustancial- han sido las razones basadas en la dificultad procedimental de cubrir plazas de manera permanente, entre el momento en que se detecta la necesidad hasta el fin del proceso selectivo -dificultad que se topa con un escollo inicial, la «tasa de reposición de efectivos», especialmente constreñida entre 2012 y 2016-, que ha comportado muy a menudo una gran dificultad de gestión para las Administraciones Públicas, con independencia de su tamaño, hasta el punto que no es imposible localizar algunas entidades en que todos sus empleados, a 2021, son temporales laborales, funcionarios interinos o indefinidos no fijos, o que Administraciones y entidades públicas -generalmente en el ámbito local- de mayor tamaño y capacidad de gestión asumen tasas del 30 o 40 por ciento de temporalidad ${ }^{6}$, aunque estas cifras se localizan también en dos de los pilares fundamentales del Estado del Bienestar y que se centran en las Comunidades Autónomas: el personal del sector sanitario y el personal del sistema educativo público no universitario (Rojo Torrecilla, 2021) y sin olvidar, por supuesto, el totum revolutum de las plantillas del personal docente y de administración y servicios de las Universidades Públicas, con figuras de temporalidad «eterna» como los profesores asociados.

Sin embargo, no debe negarse que el concepto «agilidad» en los procesos selectivos, prescrito por el EBEP, se contradice con la realidad práctica y como acredita el propio Estado al señalar que para la selección de funcionarios para Cuerpos Superiores el promedio entre la Oferta publicada en el BOE y el nombramiento, oscila en torno a los dos años, y solo se reduce a algo más de 400 días en los Cuerpos auxiliares y administrativos (AGE, 2021, p. 28). Estos periodos se prolongan aún más en el ámbito autonómico y en muchas entidades locales, con periodos que superan los tres, cuatro e incluso en ocasiones superan los cinco años para ejecutar un proceso selectivo, especialmente desde 2016, por presiones de diversas índole, generalmente internas que han solicitado -y logrado- ralentizar cuando no incluso paralizar la selección para no perjudicar al personal interino.

Entre los años 2003 y 2004 -etapa final del Gobierno Aznar-, diversos Informes del Defensor del Pueblo (2003) y del Consejo Económico Social ${ }^{7}$ (2004) analizaron tal problemática, con reflexiones y conclusiones que mantienen casi plena vigencia a 2021-2022; por ello el intento de estabilizar el empleo temporal no es una idea nueva, aunque se ha fracasado, total o parcialmente, al quedar al albur de mil y una circunstancias, especialmente cuando se ha querido evitar aplicar los principios de mérito y capacidad.

La lectura de estos dos informes es extraordinariamente interesante, porque habiendo transcurrido más de quince años, el diagnóstico y conclusiones se mantienen y prueba del enquistamiento del problema es que ya en 2005 dedicábamos un análisis a la cuestión (Boltaina, 2005); circunstancias que en gran medida persisten, cuando no exponencialmente incrementadas, en no pocas Corporaciones locales y muy especialmente en el sector sanitario y educativo no universitario de las Comunidades Autónomas y, también, entre el personal docente de las Universidades Públicas.

La dificultad comprensiva de la situación nos traslada al hecho de que muchos intentos activos de resolución, pasadas dos décadas, han reproducido el mismo -y grave- problema; así, por citar un ejemplo suficientemente ilustrativo, por su dimensión, es que la elevadísima temporalidad en el sector sanitario a inicios del siglo XXI ya se quiso solventar hace dos décadas, entre otras mediante la ley 16/2001, con un muy grande consenso parlamentario ${ }^{8}$. ¿Qué ha sucedido para que lo que fue un proceso "extraordinario» en el 2001 deba reiterarse de nuevo en el 2022, dado que hay Comunidades Autónomas que sustentan una

\footnotetext{
6 Entre otros muchos, vid. La Vanguardia de 27-6-2018: la temporalidad del Ayuntamiento de Santa Cruz de Tenerife alcanza el 30 por ciento con una antigüedad media de diez años; La Provincia-diario de Las Palmas de 15-7-2021: la temporalidad del Ayuntamiento de Las Palmas supone el 70 por ciento, con un promedio de antigüedad entre once y 26 años; La Voz de Avilés de 24-6-2018: la temporalidad en el Ayuntamiento de Avilés alcanza el 40 por ciento.

7 Aprobado por el Pleno del Consejo de 22 de diciembre de 2004; vid. www.ces.es.

8 Ley 16/2001 de 21 de noviembre «por la que se establece un proceso extraordinario de consolidación y provisión de plazas de personal estatutario en las Instituciones Sanitarias de la Seguridad Social de los Servicios de Salud del Sistema Nacional de Salud». BOE núm. 280 de 22 de noviembre de 2001.
} 
temporalidad en sanidad que supera el 50 por ciento $?^{9}$ Según informes del propio Estado, a inicios de 2021 la educación suponía una tasa de temporalidad de 428.700 personas $(31,5 \%$ del sector educativo público y privado) y la sanidad -pública y privada- alcanza a los 410.000 ciudadanos, con un 37 por ciento ${ }^{10}$. Datos que acreditan que los males del sector público se reproduce también en el privado ${ }^{11}$, si bien las fórmulas de solución son infinitamente mejores en el ámbito privado, mientras que en el público pueden colisionar, cuando no simplemente romper los principios de igualdad, mérito y capacidad.

\section{LA RESPUESTA DEL ESTATUTO BÁSICO DEL EMPLEADO PÚBLICO DE 2007 A LA TEMPORALIDAD}

El EBEP de 2007 encaró -o lo intentó- el exceso de temporalidad a través de diversas medidas, si bien no es extraño que una parte significativa de la doctrina considere que como tal Estatuto ha fracasado - «fracaso estrepitoso», lo califica Jiménez Asensio, 2018- y en esta situación -a nuestro juicio- debe incluirse también la gestión de la temporalidad, pese a que intentó poner un cierto orden.

Dos fueron los ejes que, a nuestro juicio, fueron fundamentales, porque implicaban un impulso decidido a la solución, aunque coartado finalmente por la realidad política y económica a partir de 2010:

1. La voluntad del legislador de normalizar el proceso de Ofertas de Empleo Público a fin de evitar una acumulación ad infinitum de empleados temporales de todo tipo -laborales y funcionariales- en estado de pendencia sin visualización clara de su convocatoria para cubrir de forma definitiva la plaza que ocupaba.

En este sentido, se fijó que el nombramiento de un funcionario interino en plaza vacante comportaba que esta plaza debía incluirse en la Oferta de Empleo de ese mismo año o bien en la del siguiente, salvo amortización (art.10 EBEP), aunque se olvidó -consciente o involuntariamente- incorporar tal medida en los trabajadores interinos en plaza vacante.

Por otro lado, se vinculó todo ello a que la ejecución de las Ofertas de Empleo Público se concretara en el plazo de tres años (art.70.1 in fine EBEP ${ }^{12}$ ), un precepto que dio paso a una larga litigiosidad sobre si la no ejecución en esos tres años suponían la caducidad o no de la misma, resuelta en sentido positivo, el de la pérdida de virtualidad ${ }^{13}$. Todo un conjunto de previsiones temporales con la finalidad, incluso en plazos extremos, de que la temporalidad de los empleados no superara los cinco o seis años, en el caso máximo. Un criterio legislativo que guardaba -y sigue haciéndolo- consonancia con el criterio del Tribunal Constitucional manifestado en las SSTC 240/1999 y 203/2000 ${ }^{14}$ que considera que una interinidad superior a cinco años desvirtúa el carácter de urgencia y necesidad e inserta al empleado afectado -funcionario o laboral- en un statu quo de «interino estable».

2. ${ }^{a} \quad$ La posibilidad de un turno de consolidación del empleo temporal a través de la disposición transitoria $4 .^{a}$ del EBEP con la voluntad de regularizar las plazas ocupadas por interinos y temporales con anterioridad al 1-1-2005. Un proceso cuestionado por algunos académicos (Fondevila, 2018, p. 53 y ss.) y calificado de «una puerta trasera de acceso inconstitucional», aunque no parece ser esta el criterio de los tribunales cuando han debido aplicarla, pero que en todo caso ha quedado superado, por su laxitud, por el

\footnotetext{
2021.

9 http://www.cesm.org/2021/04/14/la-temporalidad-en-fraude-de-ley-de-la-sanidad-publica-espanola/; última consulta, 12-11-

10 Tomando los datos que proporciona Brufao (2021, 27, pp. 16), en base a las referencias de Redacción Médica, en el 2017 en el sector sanitario público español había casi 185 mil temporales/interinos frente a casi 290 mil funcionarios o laborales fijos; mientras, en el 2019 se ascendía a 226 mil temporales frente a 271 mil empleados fijos. Esto es, un aumento en dos años de 42 mil empleados temporales y una disminución de fijos próxima a 18 mil.

11 https://www.eleconomista.es/economia/noticias/11363892/08/21/Sanidad-y-educacion-con-fuerte-peso-publico-los-sectorescon-mas-temporales.html; publicado el 20-8-2021, última consulta 12-11-2021.

12 Literalmente, «en todo caso la ejecución de la oferta de empleo público o instrumento similar deberá desarrollarse dentro del plazo improrrogable de tres años» (art.70.1.in fine, EBEP).

13 STS de 21 de mayo de 2019 (recurso 209/201): el TS establece que el plazo de tres años establecido en el art. 70.1 EBEP para la ejecución de la oferta de empleo público tiene carácter esencial. Por tanto, transcurrido este sin que se haya ejecutado la oferta en ninguno de sus aspectos, queda sin efecto. El TS reitera el fallo ya expresado en su sentencia de 10 de diciembre de 2018 (recurso 129/2016). En esa sentencia, el TS añadía que «son precisas razones muy poderosas para no deducir de esa disposición el carácter invalidante del incumplimiento del plazo». El TS insiste en la vinculación de la oferta pública con el ejercicio presupuestario en que se produce su aprobación, y una vez transcurrido el plazo de tres años sin que la Administración la haya ejecutado, cabe presumir que las necesidades de personal permanente han desaparecido.

14 STC 240/1999 de 20 de diciembre, BOE 20-1-2020; STC 203/2000 de 24 de julio. BOE 24-8-2020.
} 
RD-ley 14/2021 y la previsible ley que al cierre de este documento se tramita en el Parlamento Español, en donde el concurso o el concurso-oposición sin que la fase de oposición sea eliminatoria parece que serán las opciones del legislador para «resolver» - presuntamente- el problema de la temporalidad en el empleo público.

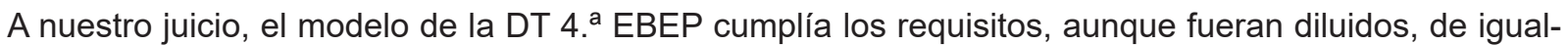
dad, mérito y capacidad. Exigía que en la fase de la oposición se valoraran los méritos de antigüedad, pero distribuidos entre «el tiempo de servicios prestados en las Administraciones Públicas» -esto es, en todas, y no sólo en la que convocara el proceso selectivo- y «la experiencia en los puestos de trabajo objeto de la convocatoria», previsión esta última muchísimo más cuestionable, pero cuanto menos objetivable, pues el propio Tribunal Constitucional ha validado esta valoración, en sus justos términos y con prudencia, pues no podemos desconocer que tan injusto es valorarlos en exclusiva -como puede suceder en un concurso de méritos- como no tenerlos en absoluto en cuenta, como acontece en las oposiciones sin fase de concurso. En el término medio, en los procesos selectivos, está quizá el sentido común, y las posiciones maximalistas de uno y otro lado mal encaje tienen en la gestión de recursos humanos, en donde -no hay que olvidarlo- se gestionan «personas» y no tributos, licencias urbanísticas o cédulas de habitabilidad.

\section{LAS SOLUCIONES DEL «PRESENTE»: DEL EBEP AL 2021}

Este periodo abarca desde el EBEP de 2007 hasta el RD-ley 14/2021. En cuanto al primero, ya hemos destacado los dos elementos clave, en cuanto a la convocatoria de plazas cubiertas de forma no permanente y la DT $4 .^{\text {a }}$ sobre consolidación del empleo.

Sin embargo, el EBEP de 2007 se promulgó a pocos meses vista de la que fue una de las crisis financieras más implacables en España y en la Unión Europea, cuanto menos en el presente siglo XXI. La reducción del déficit -a toda costa, cayera quien cayera, como supuso la afectación a los servicios sanitarios-a través de reducir las retribuciones de los empleados públicos, la reforma constitucional de 2011 sobre medidas de estabilidad presupuestaria y las normas adoptadas por el nuevo Gobierno elegido en 2011 bajo la presidencia de Mariano Rajoy supusieron una paralización, primero muy estricta y luego más moderada, de la incorporación de personal permanente.

Así, frente a la tasa de reposición «cero» de la Ley de Presupuestos para el 2012 o la excepción escuálida del diez por ciento en sectores esenciales muy concretos (art.23.uno.1 y 2 Ley 2/2019 de 29 de junio) se instituyó la posible salida, una "vía de escape» como la previsión, en esa misma tan reduccionista ley, de la posibilidad de que si bien, «durante el año 2012 no se procederá a la contratación de personal temporal, ni al nombramiento de personal estatutario temporal o de funcionarios interinos», cabía el margen de hacerlo «en casos excepcionales y para cubrir necesidades urgentes e inaplazables que se restringirán a los sectores, funciones y categorías profesionales que se consideren prioritarios o que afecten al funcionamiento de los servicios públicos esenciales» (art.23.dos), progresivamente difuminada hasta llegar al año 2017 y siguientes en que tal posibilidad se permitía con menos requisitos, como «no se podrá contratar personal temporal, ni realizar nombramientos de personal estatutario temporal y de funcionarios interinos excepto en casos excepcionales y para cubrir necesidades urgentes e inaplazables» (art.19.cuatro, Ley de Presupuestos para el 2021, 11/2020 de 30 de diciembre).

No obstante, el periodo 2007-2021 se ha caracterizado por otros flujos y reflujos que deben contextualizarse adecuadamente, pues ellos nos permiten también aprender y orientar el futuro, y cualquier propuesta para tal futuro debe tener en cuenta las enseñanzas del pasado, pues el bucle se eterniza por el referido olvido de esta experiencia acumulada. En concreto, deben destacarse los siguientes elementos:

a) La crisis económica y financiera de España tuvo un traslado, a partir del 2010 en una política limitadora de decisiones sobre el empleo público, que fueron desde la reducción de retribuciones, supresión de la paga extraordinaria de diciembre de 2012 -luego recuperada- y otras que se plasmaron en el RD-ley de 20 de mayo de 2012.

Incluso se aplicaron medidas de extraña conjunción, como el incremento de la jornada de trabajo a un mínimo de 37,5 horas semanales como mínimo (ley de presupuestos del 2012 para todas las Administraciones, posterior a la decisión de aplicarla al Estado), para luego flexibilizar el modelo en la DA 144 de la Ley $3 / 2017$, pero vinculándola a lograr una reducción de interinidad al 8 por ciento, cifra «cabalística» que se ha reiterado cual mantra hasta el momento presente, cual desiderátum sobre el que hay una escasa creencia de lograrse. 
b) Una medida muy específica fue la ya antes mencionada «congelación» de las Ofertas de Empleo público a través de la fijación de Tasas de Reposición de Efectivos nulas o muy escuálidas en el 2012 y unos pocos años posteriores. Aunque no ha sido la única responsable del incremento de la temporalidad, lo cierto es que ante la imposibilidad de incorporar personal fijo y tampoco, la «vía de escape», como hemos señalado, fue -y sigue siendo- el recurso a la temporalidad funcionarial y laboral, bajo la premisa de preceptos que preveían que los criterios antes señalados de excepción, que siendo calificados como tales, se convirtieron en ordinarios.

Aunque las cifras pueden dar como resultado que la confluencia de no incorporar personal permanente, el juego de la tasa de reposición y el recurso al personal interino y temporal incrementó exponencialmente los índices de temporalidad, lo cierto es que también se han añadido elementos suplementarios.

A nuestro juicio, no es uno menor -sino todo lo contrario- la imposibilidad del modelo español de prever, con antelación, la incorporación de personal que deba sustituir futuras bajas definitivas. En este sentido, entre 2007 y 2021 no ha habido medida alguna que permitiera a las Administraciones gestionar el futuro y limitarla exclusivamente a hacerlo mirando por el «retrovisor» de la selección.

En este sentido, la tasa de reposición es buen ejemplo de que su cálculo se efectúa en base a las altas y bajas definitivas de personal permanente del año natural anterior, y nunca del año en curso o de futuros ejercicios. Por consiguiente, si una Administración, a 2021 o 2022 conoce exactamente el número de jubilaciones que tendrá en los tres, cuatro o cinco años siguientes, no puede llevar a cabo apenas ninguna medida para lograr que cuando tal o cual empleado fijo se jubile, su sustituto lo sea también con carácter de permanencia.

c) a partir de 2016 el modelo se flexibilizó, tanto con las tasas de reposición -que sin embargo, no lograr recuperar la pérdida de empleo fijo- como con otras medidas, de las que las más destacables fueron los procesos de estabilización previstos en los artículos 19 de la Ley 3/2017 y 6/2018 de Presupuestos Generales del Estado para esos respectivos años. Especialmente esta última, que permitía estabilizar prácticamente todas las plazas ocupadas interina o temporalmente con una antigüedad de tres años a contar a partir de 31-12-2017, sin que ello implicará aplicar una tasa de reposición limitativa.

d) no obstante, tales procesos de estabilización han tenido un éxito relativo o, como contraparte, un fracaso parcial. Muchas entidades públicas no hicieron ejercicio de las posibilidades que les ofrecían ambas leyes, especialmente la Ley $6 / 2018$, y prueba de ello es que los periodos previstos para aprobar los procesos, que finalizaban respectivamente en diciembre de 2019 y 2020 , se prolongaron con posterioridad y de nuevo el RD-ley 14/2021 los ha vuelto a tener en cuenta, ofreciendo la posibilidad de aprobarlos con fecha límite de 31 de diciembre de 2021.

Todos ellos sufrieron un varapalo muy significativo cuando, promulgado el RD-ley 14/2021, muchas Administraciones, sindicatos y empleados interinos comprobaron que los requisitos de exigencia de ambas estabilizaciones eran mucho más estrictas con el mérito y la capacidad que lo previsto en el nuevo RD-ley de 2021 y, aún más, comparando con las exigencias que en sede parlamentaria se han ido imponiendo en el debate de la Ley tramitada -con origen en el RD-ley 14/2021-, para plantear el concurso de méritos para muchísimos supuestos.

Con ello, tales procesos derivados de la Ley 3/2017 y 6/2018 basados en el concurso-oposición han quedado, en el 2021, en gran medida heridos fatalmente ante las posibilidades de una norma de rango de ley convierta la excepción excepcional -valga la redundancia- del concurso previsto en el EBEP, en un criterio general para el personal temporal que ocupa plazas con tres, cinco o más años de antigüedad acumulada.

Porque no debemos olvidar que cuando se tratara de un concurso-oposición, el art.61.3 EBEP señala -porque no se ha derogado- que «la valoración de méritos de los aspirantes podrán otorgar a dicha valoración una puntuación proporcionada que no determinará, en ningún caso, por sí misma el resultado del proceso selectivo», en tanto que el art.61.6, segundo párrafo, indica-tampoco se ha modificado- que «sólo en virtud de ley podrá aplicarse, con carácter excepcional, el sistema de concurso que consistirá únicamente en la valoración de méritos». La pregunta por tanto es clave: ¿es excepcional un supuesto que puede afectar a cientos de miles de plazas?

En este sentido, hemos planteado que las leyes 3/2017 y 6/2018 ofrecían medidas razonables, que no colisionaban -cuanto menos, frontalmente- con los principios de igualdad, mérito y capacidad, para estabilizar las plantillas. En especial la Ley 6/2018 incorporaba un conjunto de criterios coherentes (Boltaina, 2021) en términos jurídicos pero también de gestión pública, transitando por la estabilización a través del concursooposición y sin que todas las convocatorias derivadas quedaran limitadas por tasa alguna de reposición de efectivos. 
Sin embargo, en este periodo -que continúa, en este aspecto- vino a incorporarse al debate -a veces incruento- las sentencias con origen en el Tribunal de Justicia de la Unión Europea y la aplicación, entre otras pero fundamentalmente, de la Directiva 1999/77/CE. Una doctrina judicial que ha ampliado los derechos de los empleados temporales -lo cual parecía ya imperativo desde antes de la Directiva-, que ha corregido a España en muchas normas jurídicas sobre empleo público bien asumidas durante años y décadas y, también, señalando la necesidad de establecer criterios que desincentivaran o sancionaran, de manera efectiva, la temporalidad prolongada.

\section{LA RESPUESTAS DEL REAL DECRETO-LEY 14/2021 Y LOS ACUERDOS PARLAMENTARIOS POSTERIORES: LOS ELEMENTOS CLAVES DE SOLUCIONES DE «MIRADA CORTA»}

El Tribunal de Justicia de la Unión Europea ha sido receptor de numerosas demandas que afectan a funcionarios interinos, personal laboral temporal e indefinidos no fijos e, incluso, personal eventual de confianza o asesoramiento especial (in extenso, vid. Fuentetaja, 2019, pp. 291-313), sobre aspectos muy diversos; muchas referidas a las diferencias -ilegales- entre el trato que recibe el personal permanente respecto del no permanente y especialmente del incremento de la temporalidad de larga duración, lo que ha supuesto, en cascada, numerosas sentencias, que siguen dictándose durante el año 2021 y que previsiblemente seguirán en los próximos años.

A ello se ha unido una compleja jurisprudencia ante una figura tan vitriólica, en su nacimiento y desarroIlo posterior, como es el de los trabajadores indefinidos no fijos (Beltrán de Heredia, 2021), a los que se han unido algunos intentos judiciales de crear también la del «funcionario indefinido no fijo» ${ }^{15}$.

Por ello y por razones también en que la dimensión de la temporalidad del empleo público no sólo se ha desbordado sino que corría -y sigue haciéndolo- el camino de conducir a la Administración a un bloqueo, tanto el Gobierno central como los sindicatos más representativos en la función pública (CC.OO, UGT y CSI-F) negociaron -a menudo en la penumbra y con escasa reflexión pública, quizá por temor al fracaso por los imputs externos que se recibían contrarios a ese posible acuerdo- una solución que se concretó en el Acuerdo de 5 de julio de 2021.

El debate se centró y sigue haciéndolo -incluso aunque se apruebe una Ley en el trámite parlamentario posterior al RD-ley 14/2021- entre como casar la protección y los derechos del personal temporal de más larga duración con los principios de igualdad, mérito y capacidad en el acceso a la función pública -entendida ésta, a nuestro efectos, tanto la funcionarial y la laboral-, una cohonestación no siempre fácil, más bien al contrario, en ese conflicto entre derechos -incluso constitucionales- que acontece en muchos ámbitos del Derecho, así como un debate nada menor, cual es hasta que punto las Directivas de la Unión Europea pueden imponerse no sólo al derecho nacional -lo que es claro- sino al propio ordenamiento constitucional, cuestión en absoluto pacífica.

A lo largo de los años 2020 y 2021, al sindicalismo más representativo (UGT, CC.OO y CSI-F) le surgió una réplica agresiva y nada pactista de «plataformas de interinos» que se han alejado de aquél sindicalismo; a ello se han unido organizaciones sindicales con escasa o nula representación, que se califican de «sindicalismo alternativo» como acredita el «Manifiesto del sindicalismo alternativo contra el abuso de la temporalidad y por la consolidación del empleo en las Administraciones Públicas» de 2 de febrero de $2021^{16}$.

A este elemento ha ayudado también un grupo de despachos de abogados que representan legalmente a decenas de miles de interinos, pero con un discurso jurídico cuanto menos de "pensamiento único» -que rechaza cualquier debate-, que da por hecho que es constitucional en España y acorde con el derecho europeo que un temporal de larga duración puede pasar a ser fijo sin más trámite, al grito en las redes sociales de «fijeza ya» y «fijeza es constitucional» y que anatemiza a cualquier criterio académico o jurídico -y político- que no comparta tal construcción (Boltaina, 2021), y que sigue luchando contra el RD-ley 14/2021 e incluso contra las enmiendas que se han ido aprobando en las diversas Comisiones del Congreso en el periodo agosto-noviembre de 2021.

15 En este sentido, la sentencia del juzgado de lo contencioso-administrativo núm. 17 de Barcelona (proc.abrev. 362/2020-F1), que estima la demanda de un funcionario interino y lo declara «funcionario indefinido no fijo».

16 Vid. https://intersindical.es/manifiesto-del-sindicalismo-alternativo-contra-el-abuso-de-la-temporalidad-y-por-la-consolidaciondel-empleo-en-las-administraciones-publicas/; última consulta, 21-9-2021. 
En este iter, debemos distinguir diversas fases, pues nos llevan a las «soluciones del presente», que deben prefijar -o acaso no, al contrario- el recorrido del futuro.

Así, el Consejo de Ministros del 6 de julio de 2021 aprobó el Real Decreto-ley 14/2021 (BOE del 7) y con entrada en vigor el día 8, objeto de inicio de un nuevo trance en el camino. Un RD-ley que al cierre de este documento ya alcanza una vigencia cuatro meses pero que será sustituido por una Ley que debía aprobarse entre octubre y noviembre de 2021, aunque posible el retraso de la misma suponga unas semanas o meses más ${ }^{17}$.

Se inició, tras la referida aprobación, la segunda fase del totum revolutum del proceso. A nuestro juicio, los elementos fundamentales de este iter legislativo han sido los siguientes:

a) una vez publicado el RD-ley, y tal como hemos expuesto, se alzaron un número muy significativo de voces en contra del texto publicado. De hecho más allá del Gobierno central -y no todos sus ministros- y de los sindicatos signatarios, el Acuerdo de 5 de julio y el RD-ley 14/2021 experimentó un fuerte rechazo, por razones muchas veces ubicadas en las antípodas, unas de otras.

En primer término, las posiciones que indicaban que el procedimiento de estabilización rozaba -o incurría plenamente- en la inconstitucionalidad, que suponía además un agravio comparativo con los empleados públicos estables que habían superado un proceso selectivo así como que los principios de igualdad, mérito y capacidad quedaban claramente reducidos al permitir una valoración de méritos del 40 por ciento sobre la puntuación final, lo que impediría -o casi- el acceso de un aspirante externo a la Administración convocante, pese a que el Tribunal Constitucional ha afirmado que el límite de lo «constitucionalmente tolerable» en la fase de méritos alcanza el 45 por ciento, si bien no debe ser siempre un mérito predeterminado, como es la «pura y exclusividad» antigüedad en el puesto o plaza convocado, aunque permitiéndose una elevada valoración de esta experiencia: por todas, por ser inicialmente la más significativa, la STC 67/1989 y entre las posteriores, la STC 27/2012 de 1 de marzo.

En el otro lado, las asociaciones de interinos, algunos despachos de abogados y sindicatos -no todos, es preciso indicarlo, pues UGT, CC.OO y CSIF han mantenido posiciones de prudencia, conocedoras de la jurisprudencia del Tribunal Constitucional- que consideran que el RD-ley no satisface las peticiones de los cientos de miles de interinos y temporales de la Administración y que tampoco cumple la directiva europea 1999/77/CE sobre medidas contra el empleo temporal y que la única solución es la fijeza automática de todos los empleados temporales. A ello se han unido voces de juristas, enmarcados en despachos de abogados, contrarios al RD-ley 14/2021, al considerarlo «ilegal» y contrario al Derecho europeo ${ }^{18}$.

Y de por medio, los posicionamientos políticos, que en privado proclamaban que el RD-ley 14/2021 alcanzaba el límite de lo que era posible, pero hacia el exterior -por razones a veces contrapuestas según el grupo político- que era inaceptable, lo que aventuraba un voto negativo -por la mínima- en sede parlamentaria, coincidiendo grupos de ideología bien diversa. Contradictoriamente -o no, según distingamos entre la acción política pública y la privada-, algunos Parlamentos autonómicos han iniciado el trámite de leyes de estabilización aún más flexibles y favorables al personal temporal, aunque sean conocedores de que el Tribunal Constitucional no considera que tales Parlamentos tengan habilitación constitucional para crear formas distintas de acceso al empleo público de las que el Estado instituya o, si acaso, permita a través de su propia Ley, al considerarse que el acceso de acuerdo con los principios de igualdad, mérito y capacidad forman parte del Estatuto funcionarial y competencia exclusiva del Estado.

b) hasta la noche del día 20 de julio, el anterior a la fechada para la convalidación o no (21 de julio), no se daba una clara perspectiva del resultado de la votación. Incluso iniciado el acto en el Congreso, la incertidumbre era total y no pocos preveían una derrota. El primer resultado fue significativo: 170 votos a favor, 170 en contra y el resto del hemiciclo abstención. Un empate fruto de que una diputada de Unidas Podemos -médica funcionaria de carrera de profesión- rompió la disciplina de voto y se sumó al bloque del no, contra la tesis del gobierno central (PSOE y Unidas Podemos) favorables al sí, pese a las enormes reticencias que el segundo de los partidos citados mantuvo desde el buen inicio y ha seguido haciéndolo.

Todo ello, en el contexto de una defensa del RD-ley 14/2021 en mano de una ministra que no lo había firmado (María Jesús Montero) y el silencio del ministro que si lo hizo (Miquel Iceta), recién nombrado Ministro de Cultura.

17 Al cierre de la redacción de este documento, el RD-ley 14/2021 se ha tramitado en diversas fases en el Congreso y está llamado a ser votado en el Pleno de 2 de diciembre de 2021. Luego pasará al Senado, con nuevo trámite de enmiendas, para su vuelta luego al Congreso y su definitiva aprobación. Previsiblemente, ésta acontecerá a mediados o finales del mes de diciembre de 2021.

18 Javier Arauz, entrevista en Confilegal, publicado el 12-7-2021. 
c) en segunda votación, el desempate se rompió porque la diputada disconforme no votó, por lo que el RD-ley 14/2021 se aprobó por 170 votos a favor frente a 169 en contra, aunque con diversas promesas verbales por parte del Gobierno que se reflejan en el acta de sesiones.

En concreto, la más significativa, la aceptación de que se iniciase el trámite parlamentario como Ley, de forma urgente, para que haya una nueva norma legal que sustituya al RD-ley, introduciendo opciones de estabilización muchísimo más flexibles y «generosas» que las previstas en el RD-ley 14/2021 especialmente en su artículo 2, y con el temor manifiesto de los sindicatos firmantes del Acuerdo por lo que podría suponer de riesgo de inconstitucionalidad ${ }^{19}$. Un proceso en sede parlamentaria no concluido al cierre de este documento y que ha supuesto incorporar un generalizado procedimiento de "concurso de méritos» y la posibilidad también de que el concurso oposición incorporase una fase de oposición no eliminatoria.

Se inició así una nueva etapa, una tercera fase que es el trámite parlamentario. Así llegaríamos al inicio de lo que es, sin duda, un periodo de incertidumbre, dudas e inseguridad para todas las partes; la que va desde la entrada en vigor del RD-ley (8 de julio), sigue con la convalidación por el Congreso el 21 de julio y se prolongará hasta la aprobación de la nueva Ley que sustituya a al RD-ley.

Estos procesos de tramitación legislativa son habituales, incluso cuando el partido en el gobierno central goza de mayoría absoluta.

Sin embargo, en este supuesto, el trámite como proyecto no estaba previsto y había razones jurídicas -además de las políticas- que lo avalaban y que ciertamente se han cumplido al tramitarse: la inseguridad jurídica que crea el RD-ley tramitado como Ley si, al final de todo el proceso, los procesos de estabilización regulados en el primero, se modifican en generosidad por la segunda norma.

Es decir, el riesgo -que muy pocas voces advertían- se ha cumplido: ¿qué administración local ha osado un proceso de estabilización al amparo del art. 2 del RD-ley si la voluntad política explícita es ir hacia fórmulas de flexibilización, recurriendo al concurso de méritos o a un concurso-oposición en que la fase de oposición no fuese eliminatoria.

d) esta complejidad se vio acrecentada por el acuerdo entre PSOE, PNV y ERC logrado en la Comisión el día 11 de noviembre de 2021, en la línea ya expuesta, de generalizar el concurso de méritos y, si acaso, reconducir procesos al concurso-oposición en que no huya fase de oposición eliminatoria, todo ello confirmado en la sesión de la Comisión de 22 de noviembre. Al cierre de este documento no podemos aportar un elemento de conclusión de como finalizará el redactado de la Ley, pero sí que nos permite plantear elementos especiales, cuando señalamos -a nuestro entender- las opciones de futuro para reconducir la temporalidad y la selección de personal permanente. Elementos claves del momento presente son, a nuestro juicio, los siguientes:

a) El RD-ley 14/2021 se transformará en una Ley muchísimo más flexible y generosa para la estabilización de los empleados públicos temporales, disolviendo los principios de igualdad, mérito y capacidad y, logrando muy posiblemente un «aplantillamiento» de cientos de miles de empleados temporales sin fase de oposición o una en que tenga un papel muy menor, residual o incluso puramente cosmético.

b) La creación de una bolsa de personal temporal, de menor antigüedad, oscilando entre uno y tres años -o quizá cinco- que supondrá un problema de gestión importante, al no verse beneficiados de los «privilegios» otorgados por la nueva Ley y que, en teoría, deberán participar en el futuro en procesos selectivos con los grados de exigencia previos al RD-ley 14/2021 y a la nueva ley, con todo lo que supone de trato discriminatorio, en términos colectivos pero también individuales.

c) La existencia de una nuevo colectivo de empleados temporales, que habrán accedido entre 2019 y años sucesivos, y especialmente tras el RD-ley 14/2021, que no verán entre sus expectativas ninguna opción de estabilización por vías «fáciles», sino volviendo a las fórmulas de igualdad, mérito y capacidad tradicionales.

19 En la prudencia, han destacado UGT, CC.OO y CSIF, cuando han afirmado que debían huirse de falsas expectativas contrarias al interés general y los riesgos que la demagogia jurídica podía ocasionar así entre otros muchos, «CC.OO lamenta mucho los discursos que generan falsas expectativas y confusión entre las personas opositoras y que no obedecen al interés general que deben perseguir (....) nuestra principal preocupación se centra en el mantenimiento del empleo público, la reducción de la temporalidad, evitar que se generen nuevas bolsas de temporalidad de larga duración en vacantes y que todo proceso que se establezca y desarrolle guarde las garantías jurídicas suficientes, para quienes quieren acceder de forma definitiva al empleo público, manteniendo los principios de IGUALDAD, MÉRITO Y CAPACIDAD» (en mayúsculas en el documento original). "CC.OO no vende humo ni juega con las expectativas de las personas». Nota del Área Pública de CC.OO del País Valencià: «Convalidado el RD-ley 14/2021 que se tramitará como proyecto de ley». 
d) Un grupo indeterminado e inmenso de ciudadanos que no prestan servicios en la Administración que han visto o verán frustradas sus esperanzas, al no poder competir en pie de una mínima igualdad para acceder al empleo público, y que ha dado pie también a la constitución de «plataformas» o apoyos sindicales en defensa del derecho constitucional al acceso libre al empleo público.

e) La continuación de un debate sobre la fragilidad del modelo selectivo, ad futurum, cuando nuevos temporales se incorporen a la Administración sin haber solventado en ninguna norma jurídica sobre las necesidades de futuro: envejecimiento de plantillas, la función de la temporalidad como simple herramienta de gestión temporal o auténtica forma de acceso previo a la condición de fijo o permanente y, en especial, las condiciones de los procesos selectivos para adquirir la condición de fijeza en la Administración.

En la elaboración de este presente documento y en otros anteriores, hemos tenido ocasión de consultar y debatir planteamientos muy diversos. Desde el consenso de que el sistema de selección al empleo público español está trufado de imprecisiones, desactualizaciones y conceptos de igualdad, mérito y capacidad escasa o nulamente actualizados al siglo XXI o incluso afirmaciones de su irreformalidad -de la selección o de toda la función pública-. Nos remitimos a las monografías y documentos publicados por académicos de referencia como Rafael Jiménez Asensio, Carles Ramió, Juan Luis Morentinos y otros profesores y juristas que plantean opciones de "ruptura», ante un modelo considerado caducado e irreformable.

Sin embargo, en este documento hemos querido plantear un último apartado de «luces cortas», pero quizá con más vista al futuro que las referidas hasta el momento. Aunque asumamos que el modelo no funciona o lo hace de manera disfuncional y poco acorde con los principios de una Administración moderna y de los principios constitucionales de igualdad, mérito y capacidad -en donde para unos el mérito es la exclusiva valoración de la antigüedad en la propia Administración convocante y para otros la capacidad es la superación de pruebas memorísticas- queremos plantear unos elementos de «futuro» que permitan, según el nuestro régimen jurídico actual, reconducir la temporalidad y la selección de personal permanente. Esto es, elementos o respuestas que son factibles con la normativa vigente -o reformas menores- y que, a nuestro entender, disminuirían la presión que supone el problema, en tanto en cuanto se debata en el futuro - ¿años o décadas?- una reformulación completa de la selección del personal de la Administración y del sector público.

\section{6. ¿LAS OPCIONES DE FUTURO?: RECONDUCIR LA TEMPORALIDAD Y LA SELECCIÓN DE PERSONAL PERMANENTE EN LA ADMINISTRACIÓN PÚBLICA}

Como hemos indicado, la primera consideración que debe efectuarse es si el empleo público español, en su conjunto, tiene opciones de futuro. Son muchos los autores que consideran que la función pública española es irreformable y prueba de ello es precisamente la COVID-19 ha puesto de relieve la importancia del empleo público pero, a la vez, de sus limitaciones, en una reflexión que es extensible a todo el sector público como tal. Carles Ramió se refería, ya en 2017, a que las Administraciones Públicas estaban en una coyuntura «en la que está en juego su propia supervivencia», con «en riesgo de desaparecer si no son capaces de generar un nuevo valor para sus contribuciones».

Este último académico, buen conocedor de la Administración, consideraba que ante los retos existentes, aquélla «carece de capacidad de reacción», "atenazada por un modelo organizativo y por un sistema de gestión de sus recursos humanos totalmente obsoleto», un ámbito este en que las Administraciones «siguen con sus inercias, con sus tradiciones y sin ninguna expectativa de romper sus pautas culturales, institucionales y organizativas de carácter mineral» (Ramio, 2017); algunas propuestas de gran interés pueden consultarse en Jiménez Asensio (2019), en su ponencia sobre «Doce tesis y seis hipótesis sobre selección de empleados públicos y su futuro», orientadora en gran medida de lo que hubiera debido ser el proceso de reorganización de la selección en los años presentes.

En este sentido, se ha afirmado también que pese a las sucesivas reformas, la función pública española sigue inalterable desde su nacimiento en el siglo XIX y el posterior Estatuto de Maura de 1918; literalmente, «disponemos por tanto de un modelo de empleo público del siglo pasado para un sector púbico que ha de enfrentar retos mayúsculos» (Catalá y Cortés, 2020, p. 9), una Administración que debe ir hacia un modelo coherente con las exigencias de los ciudadanos.

Estos últimos autores añaden como elementos que impiden tal reforma en serio y con mirada larga los siguientes: 
a) la incompatibilidad de los tempus entre los politics -cortoplacista- y el de la policy -largoplacista-, imperando la primera;

b) la inestabilidad de los cargos políticos, en constante proceso electoral; así, a inicios de 2022 contemplamos un ciclo electoral completo en la Administración local completo en mayo de 2013, en la mayoría de Comunidades Autónomas -excepto quizá Euskadi, Cataluña y Galicia- y no más allá de 2023 al Parlamento español.

c) el desgaste político que implica una reforma, con réditos inciertos -que, a nuestro juicio, añadiríamos inciertos no sólo políticamente, sino ante la ciudadanía y los propios empleados públicos-,

d) la complejidad de nuestro Estado autonómico;

e) los intereses corporativistas y particulares que desean mantener el statu quo.

f) y la «comunión de intereses» entre políticos y funcionarios, en que ambos se necesitan y se basa en un pacto «de no agresión» no escrito. A ello se puede añadir un elemento final, que en gran medida se coaliga con la letra f): la sindicalización de la Administración, con parámetros muy a menudo trasnochados y profundamente corporativistas y ajenos a la realidad de la sociedad civil, especialmente cuando se residencia en sindicatos que no son los más representativos, sino corporativistas y defensores del interés de corto alcance.

De hecho ello ha llevado a calificar el modelo español como politizado y clientelista político y sindical (Fondevila, 2020, p. 64), una politización y clientelismo ejes centrales de la gestión del empleo público que han dado por consecuencia el acceso al empleo público mediante procesos de estabilización, calificados por Jiménez Asensio como de «aplantillamiento» cuya descripción gráfica reproducimos: «enorme grupo de empleados públicos que han accedido al empleo público mediante unos sistemas de acceso sin las más mínimas garantías y que, además, en muchos casos con una clara vinculación política y sindical y dudosa cualificación profesional, lo que ha originado una pérdida de talento y profesionalidad en nuestras Administraciones y, a su vez, un fraude para el resto de los ciudadanos que han visto defraudadas sus expectativas de acceso al empleo público reconocido constitucionalmente en el art.23.2 CE» (Fondevila, 2020, p. 65, remitiéndose al prof. Jiménez Asensio).

En este camino, hay un elemento fundamental, clave incluso, cual es el acceso al empleo público. Ya hemos podido constatar que ese acceso acostumbra a acontecer, cuanto menos en la Administración autonómica y local, bajo la fórmula de la temporalidad para luego proceder a procesos ad hoc, más o menos encubiertos, de «estabilización» o «consolidación», con este nombre o bajo la fórmula de Ofertas de Empleo ordinarias, pero con altísimas valoraciones en la fase de concurso. Aunque esta fórmula se ha criticado por su fórmula (Jiménez Asensio, 2019), lo cierto es que en el ámbito autonómico y local es el habitual, y en el universitario prácticamente único.

Un modelo distinto al de la Administración del Estado, en donde muchos de los nuevos funcionarios públicos que acceden a la condición de funcionarios de carrera no han tenido contacto previo con la Administración e, incluso, tampoco contacto alguno previo con el mundo laboral, especialmente en los grupos A1 y A2. A nuestro juicio, una contraposición que no es positiva, como se acredita-generalmente en los Cuerpos de «élite»-que muchos jueces, fiscales, abogados del estado, notarios, secretarios e interventores municipales o inspectores de hacienda y de trabajo, jamás han trabajado con anterioridad -ni en el sector público ni en el privado-, habiendo pasado de las aulas universitarias a un «periodo de preparación de oposiciones», para luego integrarse en los escalones más elevados de la Administración y de la Justicia, con una falta absoluta de recorrido personal e incluso de madurez y habilidades.

Con la experiencia de lo que ha supuesto el periodo democrático (1976-2022) y las fórmulas para enfrentarse a las elevadas tasas de temporalidad, que por lo general pueden considerarse fracasadas, y las medidas ad futurum que al cierre de este artículo pueden otearse con claridad en vista del RD-ley 14/2021 sobre estabilidad del empleo temporal y el trámite parlamentario de la Ley y teniendo presente las debilidades y fortalezas del modelo, los errores cometidos y los que pueden volverse a cometer, plantearemos aquí diversas hipótesis para reconducir la problemática de la temporalidad y la selección de personal permanente si no se quiere que los procesos de estabilización del 2021-2022 no sean más que una estación tránsito para un problema que, de nuevo, en una o dos décadas vuelva a repetirse, como ya ha acontecido con el sistema sanitario público español, con la estabilización de principios del siglo XXI y la repetición, hodie et nunc, del mismo e idéntico problema, hasta el punto que el RD-ley 14/2021 no ha sido capaz de resolver la cuestión, demorando -para profesores no universitarios y sector sanitario- a un año vista la negociación del Acuerdo y la normal legal a aplicar. Esto es, como intentar evitar que la DT 4. ${ }^{a}$ EBEP 2007 no vuelva a reiterarse ahora y luego en un plazo de tiempo de nuevo relativamente corto. 
DA. Nueva Época - N. ${ }^{\circ}$, diciembre 2021 - ISSN: 1989-8983 - DOI: https://doi.org/10.24965/da.i8.11025 - [Págs. 66-91]

Personal temporal en la Administración Pública: soluciones de presente y opciones de futuro

Xavier Boltaina Bosch

\section{Reconducir la figura de la temporalidad funcionarial a sus justos términos justificativos: funcionarios causales}

Hasta el 2020-2021 no parecía que la interinidad funcionarial supusiera un problema jurídico, pues la prolongación ad aeternum no tenía consecuencias prácticas sancionadoras para la Administración, pese a que la doctrina alertaba desde mucho tiempo atrás sobre esta grave circunstancia y planteando «repensar la figura» (Cantero Martínez, 2017).

Sin embargo, en base a interpretaciones diversas de la Directiva 1999/77/CE, algunos juzgados han creado figuras ad hoc, ajenas al EBEP, de funcionarios interinos permanentes, siguiendo la estela -aunque diferente en sus consecuencias- de la figura del «funcionario interino estable» que calificó las largas duraciones una determinada jurisprudencia constitucional en los años 1999 y 2000 , antes citada, lo que ha acentuado la confusión y la comparación con los contratados laborales (Brufao, 2021, p. 39).

No puede negarse la necesidad de empleo temporal funcionarial o estatutario en la Administración, cuando hay necesidades a cubrir perentoriamente y deben ser atribuidas a personal funcionario, incluso cuando implican ejercicio de autoridad (Brufao, 2021, p. 49). Las posibilidades del derecho funcionarial son diversas y son -o deberían ser- siempre causales, esto es, con una causa específica que permita el nombramiento y con un plazo temporal máximo de permanencia ${ }^{20}$; cuestión distinta es que el estatuto jurídico del funcionariado interino adolece de un régimen estructurado, o como señala Brufao (2021, p. 37), «serio», «bien planteado» y "con racionalidad interna».

Esto es, los cuatro tipos de funcionarios interinos del art.10 EBEP -antes y después de la reforma por el RD-ley 14/2021- están plenamente justificados e incluso aceptados por los sindicatos, pero su uso se ha pervertido en dos de ellos: los funcionarios interinos vinculados a programas temporales de actuación administrativa y los funcionarios interinos en plaza vacante.

En el primer supuesto, el EBEP fue reformado una década después de su promulgación, para corregir el posible fraude de ley, que se generalizaba, con la «ingeniería jurídica» de crear «programas» de duración ilimitada. En este sentido, se aplicó un periodo máximo de tres años -ampliables hasta cuatro años si una Ley «de Función Pública» dictada en desarrollo del EBEP lo prevé-, que en la reforma del art.10 a través del RD-ley $14 / 2021$ se ha mantenido.

Con ello, la interinidad vinculada a programas temporales en gran medida se aproxima a las duraciones propias del contrato de obra o servicio determinado fijado en el art.15.1.a) del ET. Una «laboralización» de la interinidad funcionarial que supuso en su momento -y hasta la actualidad- la huida de la indemnización económica de los doce días por año trabajado que sí se prevé para el contrato temporal laboral y no para los funcionarios interinos y además, quedando excluidos de las consecuencias que prevé el art.15.5 del ET sobre acumulación de dos o más contratos de obra o servicio determinado y contratos eventuales, superando los 24 meses dentro de un periodo de 30. Cuestión distinta, y que debe merecer un profundo análisis, es la actuación selectiva consolidadora a llevar a cabo cuando tales programas temporales supongan, de facto, plazas estructurales en la organización pública.

En cuanto a la duración máxima de la interinidad en plaza vacante a tres años, que fija el nuevo art.10 EBEP, según el art.1.1 del RD-ley 14/2021 -que se mantendrá previsiblemente con la nueva Ley-, lo cierto es que ello supone una constatación del fracaso de la previsión inicial del EBEP de que toda plaza de funcionario interino en plaza vacante debía convocarse en el año en que se formalizara el nombramiento, o en el posterior salvo amortización, cohonestado con el art. 70.1 in fine, que señalaba -y sigue haciéndolo- que las Ofertas de Empleo Pública deben ejecutarse en un plazo máximo de tres años.

Con la reforma de 2021, sea cual sea la actuación de la Administración o la previsión que permita la ley, el nombramiento decae ex lege a los tres años exactos a contar a partir de la fecha del nombramiento, por lo que es un cese ad personam, con la única excepción de que la convocatoria esté desarrollándose ya durante estos tres años, en que el nombramiento mantendrá su vigencia en tanto en cuanto no finalice. Por tanto, puede considerarse que el funcionario interino queda en una situación de inferioridad de condiciones mayor que la previsión inicial del EBEP de 2007, pues su permanencia penderá exclusivamente del cumplimiento o no de las obligaciones de la Administración, aunque esta pueda incurrir en responsabilidades en base a la nueva disposición adicional $17 .^{a}$ del EBEP, incorporada por el RD-ley 14/2021.

En contrapartida, es una regla jurídica que desvirtúa las tasas de reposición de efectivos de la Ley de Presupuestos, o cuanto menos las contradice, pues si existe la obligación de convocatoria será porque la

20 En detalle, Sánchez Morón, 2020, pp. 32-40. 
tasa de reposición permite tal convocatoria y ello acarreará una situación de cierta complejidad, porque será posible siempre que el nombramiento traiga causa por uno de los elementos que «suman» en el cómputo de la tasa (fallecimiento, jubilación, etc.) pero nunca en la creación de nuevas plazas.

El efecto, indeseado -aunque quizá buscado-, de tal previsión será que sólo será plausible y razonablemente no arriesgado nombrar un funcionario interino en plaza vacante si esta plaza lo es consecuencia de una causa como las señaladas -la más general, la jubilación, fallecimiento o excedencia voluntaria sin reserva de plaza-, pero queda desvirtuada o incluso anulada la posibilidad de cubrir plazas de nueva creación, porque no desapareciendo la tasa de reposición, el triángulo para la convocatoria dependerá de un efecto ajeno al nombramiento interino y la nueva plaza: la existencia de una tasa derivada de algún supuesto previsto en la ley, como las antes dichas.

\section{Resituar la presencia del contrato laboral temporal en el ámbito de la Administración y concretar el modelo selectivo y la duración del contrato temporal}

El debate sobre la laboralización/funcionarización en la Administración se retrotrae, cuanto menos, a casi cuatro décadas, cuando se «liberalizo» la laboralidad a través de la Ley 30/1984 de 2 de agosto en su redacción original, criterio que fue corregido por la STC 99/1987. Un debate que es incluso cansino, pues se prolonga durante toda la etapa democrática, pero que acredita su realidad, cuando a 2021, la proporción de personal laboral en la Administración local, por citar el ejemplo más significativo, es superior al personal funcionario. Una situación que ha dado pie a un proceso de «funcionarización» del personal laboral fijo que, iniciado como sistema selectivo singular y restringido ad hoc en 1988 se ha extendido hasta hoy con la DT 2. ${ }^{\text {a }}$ del EBEP.

Más allá de este debate y de la opción general de la Constitución en favor de un régimen funcionarialestatutario -modelo que quizá, y sólo quizá, debería replantearse con rigor hacia el futuro-, lo cierto es que lo significativo es la presencia del contrato de trabajo temporal en el seno de la Administración y las consecuencias que ha comportado, fundamentalmente en el ámbito del fraude en la contratación temporal, eje central de un eterno debate (Campos Daroca, 2017).

Dos son los elementos que deben tenerse en cuenta en el conflicto jurídico -y también de gestión-: los contratos laborales cuando son correctos y adecuados según el esquema previsto en el art.11 EBEP ${ }^{21}$ y normas autonómicas y de régimen local concordantes y los contratos laborales en situación de disfunción, esto es, cuando tienen su origen en irregularidades, fraude de ley, conversión en indefinidos no fijos, subrogación por internalización de servicios, superación de tiempo por acumulación de contratos en un determinado periodo o, con una mayor dimensión si cabe, la presencia de contratos laborales temporales para ejercer funciones que según el art.9.2 EBEP deben desarrollarse por personal funcionario - de carrera o interino-.

Sin embargo, la temporalidad puede verse de nuevo desbordada por el recurso al contrato temporal -especialmente en pequeños y medianos Ayuntamientos- dado que el EBEP permite cualquier tipo de contratación laboral: desde los causales del art.15 ET hasta los restantes del Estatuto de los Trabajadores u otras normas laborales, como los contratos de formación, el -residual- contrato de fomento del empleo y otras opciones del sistema de relaciones laborales.

Por ello, salvo el contrato eventual por circunstancias de la producción y el contrato de obra o servicio determinado (art.15 ET), que son causales y en principio, tienen unos límites temporales que deben cumplirse -bajo castigo de sanción si se incumple, ex DA 15 del ET y la DA 17. ${ }^{a}$ del EBEP- el contrato laboral temporal por excelencia debería ser -como hubiera debido serlo hasta el momento presente- el contrato de interinidad en plaza vacante por proceso de selección o de promoción interna.

No obstante, el EBEP, tras su reforma por RD-ley 14/2021 olvida la duración máxima de este contrato -ausencia que acontecía con anterioridad también, desde 2007-, mientras sí se ha modificado el funcionario interino en plaza vacante fijando un plazo máximo de tres años.

Al respecto, hay dos elementos a tener en cuenta; en primer término, la DA 17. ${ }^{a}$ EBEP hace referencia a una duración máxima de la contratación laboral temporal, pero no indica cual es la de la interinidad laboral mencionada; pero marcando este camino, debemos recurrir a la jurisprudencia del Tribunal Supremo ema-

21 El art.11.1 EBEP es muy preciso: «es personal laboral el que en virtud de contrato de trabajo formalizado por escrito, en cualquiera de las modalidades de contratación de personal previstas en la legislación laboral...». Esto es, no excluye a ninguna modalidad, si bien algunas han sido o son de muy o casi imposible encaje. 
nada a partir de junio de 2021 que la fija en tres años, y cuyo exceso supone convertir el vínculo en indefinido no fijo (in extenso, vid. Boltaina, 2021a).

Lo anterior, sin embargo, sume dificultades aplicativas de gran calado. En primer término, hoy por hoy si se superan los tres años la Administración no se puede rescindir el contrato so pena de incurrir en un despido improcedente o incluso nulo; en segundo término, si bien la jurisprudencia reconoce el carácter de indefinido no fijo ello no puede declararse de oficio por parte de la Administración, al seguir vigente la DA 43. ${ }^{a}$ de la Ley $6 / 2018$, según la cual los órganos administrativos en «especial velarán para evitar cualquier tipo de irregularidad en la contratación laboral temporal que pueda dar lugar a la conversión de un contrato temporal en indefinido no fijo. Así mismo, los órganos de personal citados no podrán atribuir la condición de indefinido no fijo a personal con un contrato de trabajo temporal, ni a personal de empresas que a su vez tengan un contrato administrativo con la Administración respectiva, salvo cuando ello se derive de una resolución judicial»

La única respuesta jurídicamente segura pasa por incorporar una reforma al Real Decreto 2720/199822, que indique que la duración vinculada al proceso selectivo -hasta el momento, indeterminada por el Reglamento aprobado hace un cuarto de siglo- y que ha permitido interinidades laborales ad aeternum, se reduzca a tres años, medida que es perfectamente legal de igual manera que acontece con este mismo tipo de contrato en el sector privado en que la duración se limita a los tres meses y no es posible recurrir a un nuevo contrato de interinidad con persona distinta.

\section{El fortalecimiento de las bases de las convocatorias, los requisitos exigibles, el proceso selectivo y el papel Tribunales de selección de personal temporal e interino}

Si el resultado del RD-ley 14/2021 y de la ley que se derive es que cientos de miles de empleados temporales adquirirán la condición de funcionarios de carrera o personal laboral fijo, a través de procedimientos que hemos tenido la ocasión de calificar como «blandos» (Boltaina, 2018), aunque en esta ocasión se diluya aún más la exigencia del mérito y capacidad convirtiéndolo casi en inaudible, no hay elementos de certidumbre jurídica para prever que ello no volverá a repetirse en una o dos décadas de nuevo -o acaso antes-, si no se resuelve el problema en los próximos años con los nuevos nombramientos y contratos.

En este caso, habrán logrado la condición de «fijeza» un cúmulo considerable de ciudadanos en que quizá en su incorporación inicial a la Administración lo fue sin prueba selectiva, por subrogación, mediante entrevistas personales, por valoración de un currículo pero también incluso por pruebas selectivas de escaso o nula exigencia, o quizá también de mayor competencia y mayor valoración del mérito y capacidad.

En ese totum revolutum en que habrá candidatos que accedieron al empleo temporal desde un nivel de exigencia de cero a otro que podrá situarse en la tabla máxima -esto es, los menos, por cierto, posiblemente aquellos que no obtuvieron plaza en una Oferta de empleo, que superaron todas las pruebas pero no alcanzaron la nota suficiente por la limitación de plazas, léase los «aprobados sin plaza»- la estabilización que acontecerá partir del 2022 habrá roto prácticamente todos los diques de una función pública basada en la igualdad, el mérito y la capacidad.

Ante ello, entendemos que sólo hay dos posible alternativas de futuro. Quizá pudieran haber más, pero desde un punto de vista de cada Administración, sólo intuimos dos específicas, que se deriva desde una perspectiva que compartimos, cual es que con gran frecuencia la interinidad/temporalidad es el paso previo a la condición de fijeza: «una vez dentro del empleo público, la mayoría de los empleados temporales adquieren una cierta estabilidad de hecho, hasta que, en su caso, logran consolidar la plaza mediante un procedimiento sencillo de concurso-oposición, en el que se rebajan las exigencias de las pruebas de aptitud y se valoran desmesuradamente los años de servicio» (Sánchez Morón, 2019, p. 237). Y aunque ello se considera un efecto perverso y no buscado por la norma (Jiménez Asensio, 2019), lo cierto es que la realidad nos lleva a tal conclusión de forma mayoritaria en el mundo local y autonómico, y en gran medida en los empleados de las agrupaciones profesiones y subgrupos C2 y C1 de la Administración del Estado y de los Servicios de la Seguridad Social.

22 En concreto el art.4.2.b) del RD 2720/1998 señala la doble distinción. Así, en procesos de selección, «la duración será la del tiempo que dure el proceso de selección o promoción para la cobertura definitiva del puesto, sin que pueda ser superior a tres meses, ni celebrarse un nuevo contrato con el mismo objeto una vez superada dicha duración máxima. En los procesos de selección llevados a cabo por las Administraciones públicas para la provisión de puestos de trabajo, la duración de los contratos coincidirá con el tiempo que duren dichos procesos conforme a lo previsto en su normativa específica». 
La primera posibilidad, aunque la ley no lo prevea -y quizá debería, previo un profundo análisis sobre el modelo- es considerar que el acceso a la condición de empleado temporal o interino requiere unos procesos selectivos estrictos y exigentes, que superen ya no sólo los modos de entrevistas, currículum o pruebas de escasa complejidad, sino también las pruebas de valoración en base a fórmulas de tipo test.

La selección del personal temporal e interino debería basarse en pruebas rigurosas, en función de bases de convocatorias en que se acredite el mérito y la capacidad, mediante pruebas que no se reduzcan a un solo acto en un día concreto, sino que intervengan elementos de conocimiento teórico y práctico y, si es posible, también la entrevista y la valoración de méritos, a través de Tribunales que actúen con la misma profesionalidad, rigor e imparcialidad que actúan -o deberían- los órganos selectivos del personal funcionario de carrera o laboral fijo. Ello debería comportar que cada Administración reconoce y asume que la selección del personal temporal lo es casi como un paso previo a la continuidad de la carrera en el futuro como personal permanente.

La segunda opción, nada desdeñable pero que supone un cambio cultura ciudadana pero también sindical y política, es desconectar completamente el acceso a la temporalidad de cualquier expectativa futura de beneficio o plus intenso para participar en el proceso selectivo para obtener una plaza permanente.

Esto es, reducir la temporalidad y su contexto a estos justos términos: una temporalidad circunscrita a ello y que si acaso otorga un posible plus en el futuro, será circunstancial y reducido en la fase de méritos y, en todo caso, con límites temporales como el señalado de los tres años.

En este último supuesto, las exigencias de acceso pueden ser más diluidas, no tan formales ni estrictas, pero con una consecuencia clara: el aspirante conocerá desde el principio que su itinerario será relativamente corto en el tiempo -no más de tres años- y que esta experiencia que logrará -experiencia retribuida, por lo demás-, no le supondrá un plus tan intenso que casi impida el acceso de un ciudadano por el turno libre sin experiencia en esa y específica Administración pública.

Queda, sin embargo, un vacío que prácticamente nadie ha valorado o analizado: los interinos en sustitución de persona con reserva de plaza, sean laborales o funcionarios. Si bien su duración está, en principio, limitada, la cuestión se complica -y mucho- cuando la sustitución se deriva de una reserva por excedencia forzosa laboral o una situación de servicios especiales del funcionario titular o bien el empleado interino va acumulando sustituciones de diversos empleados con derecho de reserva -lo más habitual, por incapacidad temporal o bajas por maternidad-. Esto último en base generalmente a bolsas de trabajo de entrada y salida permanente.

En este caso, podría darse -de hecho, acontece- que el interino laboral o funcionarial acumula mucha antigüedad sin ninguna perspectiva y sin compensación económica -tampoco prevista en el RD-ley 14/2021-. Ante ello, la única opción es limitar estas duraciones a un plazo no superior a tres o cuatro años y, de no retornar el funcionario de carrera o laboral fijo por mantener su derecho de reserva, dar por finalizado el vínculo interino y optar por políticas internas de provisión del puesto de manera transitoria, por personal permanente de la propia entidad pública.

Unido a ello, se hace imprescindible evitar que un mismo ciudadano vaya acumulando nombramientos o contratos por la misma razón, basadas en el derecho de reserva de una cadena de funcionarios o trabajadores, como es el supuesto de bajas médicas, permisos por maternidad y cualquier otro tipo de derecho de reserva, pues el sistema, aparentemente legal, pervierte la relación del vínculo interino. Esta problemática es a todas luces gravísima en el sistema educativo y sanitario, en que muchos interinos lo son por sustitución ad aeternum de diversos empleados en cadena, en ocasiones incluso con nombramientos de un día o una semana, por baja del funcionario titular.

\section{Suprimir o reconducir la «tasa de reposición de efectivos»}

El problema originado por la temporalidad en España no se deriva, en exclusiva, de la tasa de reposición de efectivos, sino de otros muchos factores. Sin embargo, dado que para el 2022 se prevé de nuevo tal tasa -si bien, superando el 100 por ciento en algunos supuestos- y no parece que tal concepto desaparezca, este debería incorporarse al EBEP y no ser exclusivamente un elemento presupuestario fijado en la Ley de Presupuestos anual.

Incorporación al Estatuto Básico fruto de una reflexión previa y profunda sobre si es el mejor método para evitar un crecimiento del empleo público o una simple herramienta para evitar empleo fijo a corto plazo pero creador de una nueva bolsa de empleo temporal en el futuro. Por otro lado, las tasas -restringido el acceso de personal fijo- no han eliminado a los temporales e interinos existentes ni un ahorro de los gastos 
de personal (Brufau, 2021, p. 43), lo que permite calificarlas de «indigesto» sistema cuyo efecto no deseado aunque previsible ha sido un deterioro palatino de la institución de la función pública (Jiménez Asensio, 2021) y que vinculadas a las Ofertas de Empleo Público, son un «instrumento del pasado» (Jiménez Asensio, 2019).

El otro elemento es que el concepto y su configuración debe ser estable, de tal manera que cada año no se modifique la fórmula de cómputo -como ha sucedido con la promoción interna o los indefinidos no fijos-

Por lo demás, dado las disfunciones que ha originado, hay dos elementos también clave que deberían tomarse en cuenta; en primer término, analizar si la tasa de reposición debe tener en cuenta o no las jubilaciones. Dado que en la próxima década se jubilarán cientos de miles de empleados públicos, esta circunstancia debería desconectarse del cálculo de la tasa de reposición. Si tras una valoración objetiva sobre si la plaza debe pervivir tras el empleado jubilado y constatada su necesidad, sería preciso que no fuera la tasa la que limitara año tras año la sustitución de los empleados jubilados por nuevos empleados fijos.

La otra cuestión es que debería reformarse completamente el concepto de tasa si se quiere ser proactivo y no una Administración que gestiona «a remolque». La tasa, hoy por hoy, observa al pasado. No existe una tasa ad futurum, aunque se conozca perfectamente el número de empleados que en los próximos meses y años causarán baja, generalmente por jubilación.

La tasa de reposición de efectivos ha sido causante del incremento de la temporalidad, pero no tanto por limitar las convocatorias, sino por su fórmula de cálculo: el año natural anterior.

Ante ello, una Administración que conoce perfectamente sus posibles bajas para el año natural siguiente o los próximos años, no tiene capacidad de gestión. Si esas plazas van quedando vacantes, se deberán cubrir en principio con personal interino y temporal, creando de nuevo el mismo problema que ahora se desea corregir, por cuanto la jubilación, el fallecimiento o la excedencia voluntaria -entre otras causas- del año natural 2022, sólo podrán ser computadas en la tasa y en la Oferta de 2023 e iniciar el proceso de cobertura definitiva en los años siguientes. Ello supone, como mínimo, que previendo esa vacante a uno, dos o más años vista, su cobertura definitiva no disminuirá de los cuatro o cinco años una vez acontezca la vacante.

\section{La obligatoriedad de la convocatoria de las Ofertas de Empleo Público en los términos que anualmente fije la legislación aplicable}

Uno de los elementos que han acarreado el incremento de la temporalidad e interinidad es la duda -relativa- de si era obligatoria la convocatoria de Ofertas de Empleo Público en base a la tasa de reposición. Muchos gestores han considerado que la posibilidad existía, pero no era obligatorio; esto es, que la tasa era una posibilidad a utilizar, pero no una obligación de convocar Ofertas si existía.

Ello ha sucedido igualmente con los procesos de consolidación de la DT 4. ${ }^{a}$ EBEP o los procesos de estabilización del art.19 de la Ley 3/2017 y el mismo precepto de la Ley 6/2018. De hecho la prórroga de los plazos máximos en cada caso para convocar tales procesos en cada Administración -que finalizaban en diciembre de 2020 - se han prorrogado a 31 de diciembre de 2021. La razón de la prórroga es obvia ${ }^{23}$ : la ausencia de acción de muchas Administraciones ante la posibilidad prevista en las dos leyes, habiendo dejar pasar la oportunidad.

En este sentido, incluso se ha planteado si el proceso de estabilización previsto en el art.2 RD-ley 14/2021 es de obligada ejecución, o lo que pueda derivarse en la nueva Ley. En este caso, además, por un cierto elemento añadido imprevisto: una fórmula de «objeción de conciencia» por el rechazo que estos procesos de estabilización están provocando en muchos colectivos de funcionarios y empleados públicos, que en su momento superaron procesos selectivos en buena lid o simplemente, cuestionan abiertamente tales procedimientos en base a los principios de igualdad, mérito y capacidad.

En este sentido y más allá de la opción personal o política de cada empleado, la redacción de la normativa debe ser clara y contundente: si la Ley permite la opción de aprobar Ofertas de Empleo Público o bien

23 La primera prórroga aconteció en el art.11 del RD-ley 23/2020 de 23 de junio sobre energía y reactivación económica; la segunda, ya más limitada sólo a la ley del 2017 ampliando el porcentaje del 90 por ciento previsto al 100 por ciento de las plazas afectadas, a través de la DA 23. ${ }^{a}$ de la Ley de Presupuestos del Estado para el 2021: «La tasa adicional para la estabilización de empleo temporal en los términos y condiciones que regula el artículo 19.uno.6 de la Ley 3/2017, de 27 de junio, de Presupuestos Generales del Estado para el año 2017, incluirá hasta el 100 por ciento de las plazas que, estando dotadas presupuestariamente, hayan estado ocupadas de forma temporal e ininterrumpidamente al menos en los tres años anteriores a 31 de diciembre de 2016». El RD-ley 14/2021 vuelve a insistir en la cuestión y la ley que se tramita en las Cortes Generales al cierre de este documento a publicar lo hace de nuevo. 
procesos de estabilización, deben aprobarse y ejecutarse obligatoriamente y, ante posibles inacciones, articular vías de compulsión por parte del Estado o de las Comunidades Autónomas para asumir esta inacción y proceder a la convocatoria si la Administración obligada no actúa.

Cuestión distinta es si el modelo del RD-ley 14/2021 o la ley que le suceda parezca válido o no o incluso produzca rechazo por su hipotética inconstitucionalidad, pero existen otras fórmulas -la impugnación de las bases y el recurso a la vía judicial- para cuestionar la norma, pero no la inacción administrativa, como tampoco deberá ser esta falta de actuación la fórmula de gestionar los recursos humanos en el año 2022 y siguientes.

Todo ello sin perjuicio de que puede considerarse a tal Oferta de Empleo Público -en términos generales, esto es, como instrumento anual-, vista su trayectoria desde 1984 hasta el momento presente, como un «instrumento del pasado», «lento hasta la exasperación y escasamente funcional» (Jiménez Asensio, 2019) que debería sustituirse por un sistema ágil y flexible, continuado en su convocatoria, ejecución y cobertura día a día, mes a mes, y ya no enlazado con un acto único de cadencia anual, aunque quizá en el ámbito local entendemos que debería buscarse una fórmula unificadora de publicidad que evitara la dispersión entre miles de entidades locales ${ }^{24}$.

\section{La regulación jurídica de la figura del «trabajador indefinido no fijo». La interdicción de creación judicial de nuevas figuras de empleados públicos en el ámbito funcionarial interino}

La figura del trabajador indefinido no fijo es fruto de la creación jurisprudencial en 1996, a través de la STS de 7 de octubre de 1996 y consolidada luego con las muy conocidas STS de 20 y 21 de enero de 1998 y así ha seguido hasta el 2021-2022. Como construcción jurisprudencial, iniciada en el ámbito de la Sala Social del Tribunal Supremo, se ha ido ampliando en algunas sentencias de la jurisdicción contenciosoadministrativa (Sánchez Trigeros, 2017, p. 4).

Llegados a 2022, la figura ad hoc, de estricta creación jurisprudencial, alcanza más de un cuarto de siglo de virtualidad y su estudio ha merecido muchos diversos análisis -por su profundidad y detalle, vid. la monografía del profesor Beltrán de Heredia, 2021, y con anterioridad Desdentado, 2018-. Además, la figura ha evolucionado en muchos elementos, pasando de una extinción no indemnizada hasta su reconocimiento, como también la posibilidad del derecho a la promoción interna y otros derechos vinculados a su condición de no fijeza, de igual manera que se han ampliado los derechos de los trabajadores temporales. Pese a que se formulan muchas críticas a la figura, por su inseguridad, también ha encontrado elogios, por algunas consecuencias positivas: la correcta calificación de que el contrato de trabajo indefinido no es fijo y el fortalecimiento del principio de estabilidad en el empleo (Cavas Martínez, 2017, p. 30) y evitar que contratados temporales se transformen en fijos de manera automática (Cantero, 2021).

Dicho esto, el EBEP fue absolutamente alicorto. Ni tan siquiera los arts. 8 y 11 que señalan que el personal laboral puede ser fijo, indefinido y temporal se referían expresamente a este tipo de personal, sino al personal de los centros públicos en la asignatura de religión ${ }^{25}$. En el texto del EBEP ninguna medida más se incorpora al respecto y de hecho, han sido leyes posteriores las que, indirectamente -así, art.15.5 ET y DA 15 del mismo texto legal laboral- o leyes presupuestarias con redacción expresa a esta figura jurídica, las que han incorporado el concepto de trabajador indefinido no fijo. Esta fórmula de empleado público -pues lo es-, sin embargo, adolece de graves dificultades interpretativas y de inserción en la Administración -de nuevo, vid. Beltrán de Heredia, 2021- y continúa en constante evolución, especialmente a través de la doctrina europea del TJUE que va adoptando, no siempre con entusiasmo, por el Tribunal Supremo.

24 La propuesta de Jiménez Asensio (2019) de hecho nos retrotrae al sistema anterior a la Ley de función pública de 1984 (ley $30 / 1984$ de 2 de agosto). Lo cierto es que la cadencia anual de la referida ley estatal fue una fórmula de estabilidad y seguridad para los candidatos a acceder a la Administración a partir de 1984 -muy bien recibida ante la incertidumbre anterior a esa fecha-, que ha demostrado su virtualidad efectiva en el ámbito del Estado -que ha cumplido generalmente año tras año con su obligación- pero no así en el ámbito local y con dudas en el autonómico. Compartimos el criterio del referido académico si bien lo cierto es que en el estricto ámbito de la Administración local, con más de 8.000 entidades locales, el totum revolutum quizá debería ser a la inversa: una Oferta conocida por todos que agrupara y fuera pública para todos los ciudadanos, sea cual fuese el municipio, provincia, comarca u entidad convocante.

25 El concepto «indefinido» fue incluido en el trámite del Senado por dos enmiendas del PNV para incorporar al ámbito del EBEP al personal de la asignatura de religión de los centros públicos. Poco después se reguló por el Real Decreto la relación laboral especial de este tipo de empleados. Pese a ello, no son pocos los autores e incluso sentencias que indican que el EBEP incorporó la figura del indefinido no fijo, pero en absoluto fue la voluntad del legislador del Estatuto Básico. 
La clave de esta figura es que son un número de ciudadanos nada despreciable; aunque no hay cálculos ciertos, sino sólo aleatorios o intuitivos, a buen seguro en el 2022, los gestores públicos deberán enfrentar la realidad de decenas de miles de trabajadores indefinidos no fijos, incrementados sin duda tras la jurisprudencia del Tribunal Supremo que convierte a un interino laboral en plaza vacante que supera los tres años en indefinido no fijo (de nuevo, vid. Boltaina, 2021a). Sin olvidar los que lo son de facto, pero que prestan servicios bajo fórmulas de contratación administrativa, esto es, «falsos autónomos» o aquellos trabajadores presuntamente «fijos» a los que nadie cuestiona su statu quo, cuando en realidad no accedieron por Ofertas de Empleo Público, cuanto menos desde 1984.

Al respecto, y sin perjuicio de su condición jurídica, todas las normas de estabilización que se aprueben deberían instituir la obligación -no la voluntariedad- de incorporar a los trabajadores indefinidos no fijos. Por lo demás, debería superarse la previsión de la ley de presupuestos del 2017 y 2018 -que continúa vigenteque sólo es indefinido no fijo el que ha sido declarado así por sentencia judicial firme. Debe ampliarse la posibilidad a la Inspección de Trabajo y, también, de manera excepcional, a la propia Administración causante del nacimiento de tal figura, si se cumplen escrupulosamente las reglas que la jurisprudencia ha fijado para estos supuestos.

La mejor solución sería, sin duda, que la propia Ley establezca los criterios para determinar quién es y quien no es indefinido no fijo, una medida que adolecería seguro de olvidos, pero otorgaría seguridad jurídica a los gestores públicos en muchos supuestos - de entrada, los interinos en plaza vacante que superan los tres años- que deberán llevar a cabo procesos de estabilización. Se resolvería también así una cuestión nada menor: ¿es indefinido no fijo el trabajador aparentemente fijo que ingresó antes de la sentencia de 7 de octubre de 1996 -inicio de la jurisprudencia sobre la cuestión-, sin pruebas selectivas y que se considera él -y quizá también la organización pública- como fijo, y no indefinido?

Si bien esta última posición de la posible autodeclaración no es compartida por muchos académicos administrativistas, lo cierto es que tal pureza legalista conlleva a un resultado desconcertante en el plano de la seguridad jurídica: la existencia de facto de miles de indefinidos no fijos porque así lo considera ex lege el ET o la jurisprudencia y sin opciones por parte de la Administración de reconocer tal condición y creando una ficción de que se trata de empleados temporales, pese a que legal o jurisprudencialmente no lo son y evitar judicializar la solución, dado que sólo a través de una sentencia se da seguridad jurídica al empleado y al ente público, cuanto menos con la normativa actual derivada de la Ley 6/2018.

No obstante, no parece razonable en términos jurídicos y en base al principio de seguridad que por vía judicial se creen figuras no previstas en la ley, recurriendo a modelos de derecho comparado que no son los propios de España ${ }^{26}$. Ha sucedido en 1996-1998 con el trabajador indefinido no fijo y ahora parece acontecer -a 2021, aún tímidamente- con los supuestos funcionarios interinos indefinidos no fijos, por lo que apostamos por un cumplimiento estricto del EBEP a todos los efectos, que fija las figuras existentes, en base a las causas legales y duración máxima de nombramientos y contratos ${ }^{27}$ (Mateos Martínez, 2020, p. 418) o incluso también de «funcionarios de hecho», reconocida por alguna sentencia del Tribunal Supremo ${ }^{28}$ y más visualizable en la doctrina judicial de los Tribunales Superiores de Justicia ${ }^{29}$-vid., en detalle, Cabrera Domínguez, 2020, pp. 407-414-.

\section{La exigencia de responsabilidades por los incumplimientos en la contratación laboral temporal y el funcionariado interino}

La medida ya aparece en la ley de presupuestos de 2017 y 2018, y en normas anteriores. Esta última mantiene su vigencia con carácter indefinido. Sin embargo tales medidas se dirigían exclusivamente al

26 Analizando, sin embargo, esta figura, Sánchez Morón, 2019, pp. 223-238.

27 Para Cabrera Rodríguez, 2020, p. 394, esta traslación ha sido rechazada por el Tribunal Supremo, criterio que al cierre de este documento parece mantenerse, aunque no así entre algunas sentencias de órdenes inferiores que tarde o temprano llegarán al Alto Tribunal.

28 Así, la STS (contencioso-administrativo) de 19-12-1988, FJ 2. : «desde el punto de vista subjetivo resultan aplicables los principios que han inspirado la construcción de la figura del funcionario de hecho que ya tuvo antecedentes en el Derecho Romano».

29 La STSJ Cataluña (c/a) de 9-6-2016, FJ 5. ${ }^{\circ}$ señala que «para que una persona sea considerada funcionario de hecho (....) se señalan las siguientes condiciones: que el cargo que ocupe tenga, cuando menos, una existencia de derecho o, por lo menos, esté reconocida por la ley; que el agente se encuentre realmente en posesión del mismo; y que lo detente bajo apariencia de legitimidad de título. A ello debería añadirse que, siendo la figura del funcionario de hecho perfectamente admisible, ello lo será siempre que quien ocupa el cargo con investidura irregular lo haga en beneficio de un interés público». 
personal laboral temporal, advirtiendo a las Administraciones sobre la responsabilidad que se deriva por los incumplimientos y, en especial, por la conversión de trabajadores temporales en indefinidos no fijos.

La DA 17. ${ }^{a}$ EBEP incorporada por RD-ley 14/2021 y su mantenimiento en una futura Ley adolece una grave dificultad, apenas reflexionada por quienes han comentado o analizado la norma.

Se impone la «sanción» -si bien la norma señala el concepto «compensación»- en aquellos supuestos en que los nombramientos de funcionarios interinos o personal laboral temporal han incurrido en irregularidad en cuanto a su duración, instituyendo una «compensación» de veinte días por año trabajado con un máximo de doce mensualidades.

Teniendo en cuenta la cadena de responsabilidades que pueden derivarse -de todo tipo: administrativas, económicas, responsabilidad contable e incluso penales-, ¿cuántas Administraciones Públicas concretarán por escrito y resolución pública la autodeclaración mencionada asumiendo esta irregularidad?

La lógica nos lleva a concluir que salvo contadas excepciones en que sea posible cumplir la norma sin responsabilidades individuales posteriores, las entidades públicas negarán tal incumplimiento y derivarán cualquier circunstancia a una sentencia judicial, que deberá impulsarse por el ciudadano afectado. Posiblemente prueba de ello es que las medidas incorporadas en las leyes de presupuestos hasta el momento han tenido escasísimo recorrido aplicativo, salvo excepciones en donde la irregularidad ha sido más penal que administrativa.

\section{La regulación de las «bolsas de trabajo» o su plausible supresión}

Desde siempre se ha puesto en evidencia el torticero uso de las bolsas de trabajo como forma de acceso al empleo público temporal, pese a que su filosofía no es, en principio, errónea, aunque la realidad ha superado la bondad inicial. Así, bolsas convocadas con escasos requisitos de exigencia, en que se han acumulado déficits importantes, como los siguientes, a título de ejemplo:

- Bolsas de duración determinada en el tiempo -dos o tres años-que luego se prolongan en el tiempo ante la ausencia de candidatos para cubrir plazas vacantes.

- Requisitos de acceso muy laxos, con entrevistas o bien tipos test en donde se valora escasamente la capacidad, cuando no la simple valoración de méritos de un currículum.

- El flujo y reflujo de incorporación a las bolsas de empleados interinos o temporales que no superan un proceso selectivo, pero que mediante pactos sindicales vuelven a incorporarse a las bolsas en las mejores posiciones - gracias a sus méritos por «antigüedad»- en una situación de bucle constante, que parece consolidarse cuanto menos cuando el art.2 del RD-ley 14/2021 prevé que será posible pactar que los empleados temporales que no superen el proceso de estabilización podrán incorporarse a bolsas de trabajo ad hoc sólo para ellos o bien a otras bolsas ya existentes.

- El uso de bolsas para una determinada categoría o cuerpo o escala para cubrir vacantes de otra categoría o cuerpo, incluso para cubrir plazas de inferior categoría o grupo de clasificación de la bolsa objeto de inicial convocatoria. Se rompe así cualquier principio de igualdad y mérito, porque muchos ciudadanos no se presentaron a tal o cual bolsa convencidos que no les interesaba tal oferta, al desconocer que quizá al cabo de unos meses o años, quien está incluido puede tener mejores condiciones para integrarse en la Administración.

- La oscuridad y dificultad de acceso en qué orden y en qué condiciones son llamados los ciudadanos que forman parte de una bolsa de trabajo, de tal forma que se convierte en un proceso cabalístico conocer quién es el aspirante que debe ser seleccionado en el orden secuencial, lo que da pie a alteraciones del orden. Ello ha llevado a paradojas: desde la posibilidad de modificar el orden de llamamiento en base a previas entrevistas y elección entre diversos aspirantes en función de esta entrevista, hasta la radicalidad de que sin tener ningún contacto directo con el aspirante ni conocer nada sobre sus competencias ni habilidades -haber superado, por ejemplo, un solo test de preguntas múltiples-, se insertan en un orden en la lista al cual deben ser llamados, sea cual sea su condición o adaptación para el servicio público.

Las bolsas de trabajo, sin embargo, asumen una importante función: son previsiones de «futuro». Una Administración puede convocar una bolsa de trabajo conociendo que tendrá en los próximos años unas determinadas necesidades.

Ello es su fortaleza, que contrasta con las debilidades antes señaladas. Reducen la obligación, en este sentido también, de aprobar diversas convocatorias selectivas para cada necesidad y posiblemente, debe- 
DA. Nueva Época - N. 8, diciembre 2021 - ISSN: 1989-8983 - DOI: https://doi.org/10.24965/da.i8.11025 - [Págs. 66-91]

Personal temporal en la Administración Pública: soluciones de presente y opciones de futuro

Xavier Boltaina Bosch

rían impulsarse desde entidades supramunicipalistas o las Comunidades Autónomas unas bolsas de trabajo a que pudieran recurrir las entidades de ámbito inferior, evitándoles así la convocatoria de miles de bolsas de trabajo en función de cada Administración, especialmente en el mundo local. Un desiderátum que colisiona, a menudo, con las reticencias de cada Administración de ceder su competencia selectiva, en favor de otra entidad de orden superior y de incorporar un aspirante que no ha sido seleccionado por la propia entidad.

\section{9. ${ }^{\circ}$ Superar los desiderátums porcentuales: el 8 por ciento de la Ley 6/2018 y normas posteriores}

El porcentaje del 8 por ciento se arrastra desde hace años como supuesta cifra «mágica»; obtener la información necesaria para conocer la razón por la cual ese 8 por ciento es una cifra adecuada se nos ha hecho ininteligible, pese a que la doctrina, por lo general, parece asumirla como cifra razonable y sobre la que hay un amplio consenso que no puede negarse (por todos, Cantero, 2021).

Sin embargo, pese a nuestras discrepancias, el porcentaje ya apareció en la Ley 3/2017 y Ley 6/2018 y se ha reiterado en el RD-ley 14/2021. Esto es, el «mantra» común es que ese 8 por ciento es idóneo, una cifra asumible por nuestro empleo público. El propio Estado afirma que no tiene, como tal Administración General, un problema de temporalidad, porque sus plantillas se ubican por debajo del 8 por ciento ${ }^{30}$.

No compartimos en absoluto este porcentaje, como cifra incuestionable y lógica, aunque no negamos que sería un loable fin alcanzarla, aunque sin recurrir a procedimientos que Cantero (2021) califica de «brocha gorda», a través de un «aplantillamiento casi directo del personal temporal» con la finalidad de lograrlo. A nuestro entender, sin embargo, la temporalidad en la Administración debe basarse en elementos objetivos; es posible que en unos supuestos una temporalidad del tres por ciento sea excesiva y en otros que lo sea del 40 por ciento y sea perfectamente razonable. Esto es, la «temporalidad» es una herramienta de la gestión de los recursos humanos, en el sector público y en el privado que no se basa en porcentajes.

Cierto es que España ha batido desde hace décadas los porcentajes de temporalidad en el sector privado y en la Administración y ello debe insertarse, más que en razones jurídicas -o no sólo en ellas- sino también en razones de "cultura» social, económica, empresarial y pública. Por razones muy diversas, el empresariado privado español se impregna de un temor a «ligarse de por vida» -frase cada día más falsacon un trabajador, pero ese temor es aún más elevado en el ámbito público y especialmente con la selección de un funcionario de carrera, que asume un statu quo de permanencia que puede alcanzar desde su ingreso hasta la jubilación.

No hay ausencia de razones a la resistencia, en vista del Estatuto funcionarial, a su dificultosa ductilidad, las imposibilidades de adaptación a las nuevas realidades, el contexto altamente sindicalizado y las tendencias corporativistas, que crean un cierto temor al vínculo funcionarial de carrera -y en menor medida, al personal laboral fijo-, por ser un «matrimonio de por vida». En este sentido, la existencia del despido del personal laboral fijo en la DA 16. ${ }^{a}$ ET no es ajeno a que en muchas Administraciones se opte por la laboralización frente a la regla legal de prevalencia del vínculo funcionarial.

Las normas legales, por su frialdad y su carácter en teoría aséptico, no acogen elementos externos, como el cultural o los expuestos aquí, una cuestión que Beltrán de Heredia ha estudiado en diversos documentos e intervenciones, pues a las decisiones políticas y organizativas se acumulan criterios y sensaciones, incluso intuiciones o sesgos, que se proyectan en la decisión final. Y el temor a una vinculación de «por vida», tan deseada por el empleado, se contrapone a la decisión del dirigente político o del gestor técnico.

La crisis del 2010-2016 acredita que, por ejemplo en el ámbito local, el descenso de empleo público laboral fue del 20 por ciento, mientras que tal descenso no acontecido en el funcionariado. No es extraña tal conclusión: la reforma laboral del 2012 incorporó, como ya hemos señalado, por vez primera de manera inconfundible, la DA 20. ${ }^{a}$ ET que permitía el despido de personal laboral fijo por causas económicas, técnicas, organizativas y de producción e impidió la suspensión contractual a través de la DA 21. ${ }^{\mathrm{a}}$.

Muy significativamente y a nuestro entender, de manera claramente errónea -salvo excepciones en entidades públicas que actuaran en el mercado-, no se permitió la suspensión contractual -DA 21. ${ }^{\text {a }}$ - de los empleados laborales fijos. Esto es, la opción del legislador del 2012 fue «permanencia o despido». Y pese a esta dicotomía, el uso del despido a través de la DA 20. ${ }^{a}$ en relación al art.51 y 52.c) del ET fue muy intensa, pero la mayoría de los trabajadores laborales expulsados del empleo público fueron

30 En este sentido, la Ministra Montero en el debate sobre el RD-ley 14/2021 ante el Pleno del Congreso, 21 de julio de 2021. Idem, comparecencias de altos cargos del Estado en debates previos en sede parlamentaria. 
DA. Nueva Época - N. ${ }^{8}$, diciembre 2021 - ISSN: 1989-8983 - DOI: https://doi.org/10.24965/da.i8.11025 - [Págs. 66-91]

Personal temporal en la Administración Pública: soluciones de presente y opciones de futuro

Xavier Boltaina Bosch

contratados laborales temporales e indefinidos no fijos, lo que no sucedió en modo alguno con los funcionarios de carrera y en muchísima menor medida -en comparación con los laborales temporales- con los funcionarios interinos ${ }^{31}$.

Si bien el 8 por ciento -que además se ha vinculado a otros elementos, como la jornada de trabajo prevista en la DA 144 de la Ley 6/2018- debe calcularse en términos individuales -esto es, por cada Administración-, si lo elevamos a términos «macro», resultaría que el legislador y los sindicatos asumen como aceptable que, si nuestro empleo público ronda los tres millones de empleados, unos 240 mil podrían ser interinos o temporales ocupando puestos estructurales. Reiteramos que es un cifra «macro», porque se calcula por elevación, pero la clave es si esta cifra es razonable, lógica, coherente, funcional y suficientemente adaptada para unos servicios públicos de calidad.

Ello nos supone visualizar que una Administración local de diez empleados, no debería a partir de 2024 tener en plantilla ningún interino o temporal para no superar el 8 por ciento; esto es para cumplir el requisito de un 8 por ciento una Administración deberá tener una plantilla de cuanto menos trece empleados, para poder incorporar un interino o temporal y no exceder del referido 8 por ciento. En el extremo, una Administración autonómica, su margen de actuación será muy elevado, pues si tomamos en cuenta la Generalitat de Catalunya, con 160.000 empleados, el 8 por ciento le permitiría una plantilla temporal de casi 13.000 interinos o temporales, cuando su cifra actual ronda los 60.000 .

Esto es, el 8 por ciento es una cifra que se descontextualiza cuando se desciende a la realidad práctica de cada Administración, la estatal, las autonómicas y las locales y universitarias -en el ámbito no docente-. Por consiguiente, entendemos que estos deseos porcentuales - que muy a menudo no se logran- no responden a criterios objetivos ni racionales y parecen reconducir la temporalidad a una cifra porcentual «idílica» pero que en cada situación, periodo, entidad o circunstancia puede estar justificada o no. A nuestro juicio, los porcentajes colisionan con el uso razonable y objetivo de la temporalidad y, en el caso presente, permite afirmar a la Administración General del Estado que ya lo cumple en el 2021, razón por la cual por ello se aprobó esta cifra, traspasando el problema a las Comunidades Autónomas y Corporaciones locales como presuntas incumplidoras del número mágico previamente perfilado.

\section{La reformulación al siglo XXI de los conceptos de «igualdad», «mérito» y «capacidad»}

Vamos a finalizar este documento con unas breves referencias a los principios de igualdad, mérito y capacidad. Son principios que se predican en el acceso al empleo temporal y al empleo fijo, tanto de trabajadores como funcionarios de la Administración. La gran mayoría de las críticas al RD-ley 14/2021 y a la nueva ley derivan precisamente por considerar que estos principios se reducen, cuando no desaparecen, con la posible estabilización de cientos de miles de empleados temporales (SAF, 2021). Principios que rigen el acceso a la Administración y que no son negociables ni libremente disponibles, ni para el Gobierno ni para el legislador (Cantero, 2021). De hecho, la Dra. Cantero plantea con claridad que la igualdad en el acceso es una dimensión específica del derecho a la igualdad de trato al ciudadano, que entronca directamente con las bases del Estado de Derecho e institucionalmente uno de los fundamentos objetivos del orden jurídico ${ }^{32}$.

La cuestión estriba qué entendemos por igualdad, mérito y capacidad, lo que afecta claramente a la finalidad de «repensar» la selección de los empleados (Jiménez Asensio, 2018). Sobre ello se podría teorizar mucho, alabar o despreciar el modelo español de las «oposiciones»-que no siempre es una «oposición» y puede ser un «concurso-oposición»-, criticar o defender los procesos de estabilización, plantear la inconstitucionalidad de medidas como la DT $4 .{ }^{a}$ EBEP (Fondevila, 2018, antes citado) y, por supuesto del RD-ley $14 / 2021$ y de la futura ley que pueda surgir del trámite parlamentario, como así ya apunta el Informe del Sindicato de Funcionarios de Andalucia (SFA, 2021).

Estos principios, que se incorporaron en el art.14, 23.2 y 103.3 de la Constitución asumieron una importancia capital en 1978. Frente a una función pública franquista, con escaso rigor en el acceso, politizada y en muchos supuestos creadora de colectivos de empleados públicos cuyo acceso colisionaba con cualquier principio ya no de mérito y capacidad, sino de igualdad -nos remitimos, por dar un dato, a la prohibición de acceso de la mujer a determinadas profesiones en el empleo público y las razones que se daban para

31 Las disposiciones adicionales 20. a y 21. a del ET tras la reforma laboral del 2012 aparecen, en el texto refundido de 2015 actualmente vigente, en las DA $16 .^{\mathrm{a}}$ y 17 . $^{\mathrm{a}}$.

32 En este mismo sentido, STC 302/1993 de 21 de octubre. 
DA. Nueva Época - N. 8, diciembre 2021 - ISSN: 1989-8983 - DOI: https://doi.org/10.24965/da.i8.11025 - [Págs. 66-91]

Personal temporal en la Administración Pública: soluciones de presente y opciones de futuro

Xavier Boltaina Bosch

postergarla ${ }^{33}$-, la Constitución proclamó como derechos fundamentales de protección máxima la igualdad, el mérito y la capacidad.

Aunque se aleja del objetivo del presente documento, lo cierto es que estos principios del año 1978, a nuestro juicio, han quedado superados en su configuración, en la España de la tercera década del siglo XXI. Al respecto pueden detectarse los siguientes elementos que deben merecer una reflexión que se escapa de nuestras posibilidades aquí, pero que deseamos apuntar:

a) ¿El mérito y la capacidad debe acreditarse a través de la clásica «oposición» o si acaso del «concurso-oposición», denostándose el "concurso» de méritos por sus connotaciones de resultados a menudo predeterminados?

b) La posibilidad de explorar en el derecho comparado europeo -fundamentalmente- otras fórmulas de mérito y capacidad distintas a las pruebas memorísticas y la existencia de vínculos posteriores que ya no sean «de por vida» sino vinculados a otros elementos, como la evaluación del desempeño.

c) El papel que debería tener el vínculo temporal previo. ¿puede ser una fórmula adecuada de acceso inicial como periodo «de aprendizaje» previo a la fijeza, como acontece en funciones públicas comparadas? Esto es, la posibilidad de generalizar el acceso al empleo público, especialmente en los grupos A1 y A2 de la Administración española a través de fórmulas de temporalidad y procesos posteriores de aprendizaje, trabajo y evaluación y la sucesiva superación de pruebas y demostración de conocimientos, méritos, habilidades y competencias para lograr, al final de un recorrido -no siempre corto- ingresar de manera estable o decaer el nombramiento.

d) Y, entre otras muchas más cuestiones, cómo incorporar el talento de la ciudadanía al servicio público, teniendo en cuenta que la competencia retributiva entre sector público y sector privado no podrá ser idéntica -como tampoco los «privilegios» en días de vacaciones, festivos, días de asuntos propios y de antigüedad del sector público, lo que reduce la productividad de manera alarmante, pues un empleado de treinta o más años de servicios puede llegar a acumular entre vacaciones y permisos prácticamente dos meses de días no laborables- debiendo tener presente que los principios de «mérito» y «capacidad» son principios constitucionales y que ningún doctrina del Tribunal de Justicia de la Unión Europea podrá imponer a España una interpretación distinta, ni anularlos, ni validar el mantra que corre por las redes de que «fijeza es constitucional», porque son derechos fundamentales, de protección máxima, en los que una Directiva europea no puede imponer su infracción y su subversión.

En todo caso, compartimos con Cantero (2021), que la jurisprudencia del Tribunal de Justicia de la Unión Europea no está exigiendo la conversión de los empleados temporales en funcionarios de carrera o laborales fijos sin proceso de selección. La doctrina europea no es una «puerta falsa» para el acceso permanente a la Administración sin mayor trámite, lo que supondría de hecho socavar las bases del Estado de Derecho mismo, rompiendo el principio de igualdad: «dando cobertura a posibles comportamientos arbitrarios, nepóticos o clientelares de la Administración (...)» (Cantero, 2021).

En esta misma línea, el derecho comunitario no impone la conversión en fijos de los empleados públicos víctimas de abuso, ni tan solo exige un trato idéntico entre funcionarios interinos y laborales temporales o indefinidos no fijos. En el respeto al principio de igualdad, mérito y capacidad, el legislador puede -o debería hacerlo- buscar soluciones equivalentes que sean eficaces para evitar el abuso y sancionarlo y que sean compatibles con los principios que rigen el modelo constitucional de acceso al empleo público en España (Cantero, 2021).

Por consiguiente, las posibles medidas a tomar por el legislador -fundamentalmente, convocatoria de procesos selectivos en supuestos de fraude o irregularidad, transformación de los empleados temporales en indefinidos no fijos en el supuesto del personal laboral temporal incluso extendiéndolo al funcionario interino y concesión de indemnizaciones equivalentes al despido improcedente en el derecho laboral, aplicables a funcionarios interinos y laborales temporales-, no deberían colisionar con los principios de igualdad de opor-

33 La ley 96/1966 de 28 de diciembre suprimió la prohibición de acceder las mujeres a la carrera judicial. Es especialmente interesante la argumentación de la Exposición de Motivos por la cual a hasta ese año 1966 no era posible tal acceso: «(...) Tal excepción respondió, sin duda, no a la idea de una falta de capacidad o responsabilidad de la mujer para desempeñar tales cargos, sino más bien a una protección de sus sentimientos ante determinadas actuaciones que el cumplimiento del deber haría ineludibles». "Los motivos de la protección que la Ley quiso dispensar a los sentimientos de la mujer deben estimarse superados por la propia realidad social y porque la mujer que se sienta llamada al ejercicio de la función judicial habrá de encontrar en ella ocasiones de satisfacer su vocación, que la compensarán de las aflicciones que pueda depararle». 
tunidades en el acceso al empleo público y parece meridianamente claro «que la conversión automática del personal temporal en personal fijo o en funcionario de carrera no lo es» (Cantero, 2021).

La clave está, por tanto, en cómo debemos reformular el mérito y la capacidad en la España del siglo XXI, tanto para acceder a la condición de empleado temporal o empleado permanente, mediante fórmulas que otros países europeos han implementado con éxito frente a las rémoras del modelo español, anclado en pruebas memorísticas y la ruptura del principio de igualdad en el acceso a las funciones públicas de mayor nivel y cualificación -judicatura, fiscalía, notaría, inspección de hacienda, abogacía del Estado, entre otrasque requieren dedicación en exclusiva en la preparación con un coste que deben asumir, en exclusiva -o casi, si no hay becas- los ciudadanos aspirantes, lo que ubica a los candidatos a determinados estratos sociales en que se pueden permitir procesos de preparación de dos, tres o más años a costa de la familia que los mantiene, pero que también se extiende a los puestos de agrupaciones profesionales -antiguo grupo $\mathrm{E}$ previo al EBEP- y C2 y C1 en que la mala imagen que la Administración ostenta en los procesos selectivos desincentiva a los aspirantes externos, que pueden ser excelentes candidatos, ante el temor de que su acceso será imposible -o casi- por un funcionamiento interno de los Tribunales y adjudicación final de plazas alejado de los principios constitucionales mencionados ${ }^{34}$.

\section{REFERENCIAS BIBLIOGRÁFICAS}

ADMINISTRACIÓN GENERAL DEL ESTADO - AGE (2021). Orientaciones para el cambio en materia de selección en la Administración General del Estado. https://www.mptfp.gob.es/dam/es/portal/funcionpublica/secretariageneral-funcion-publica/Actualidad/2021/05/orientacionescambio.pdf

Beltrán de Heredia, I. (2021). Los indefinidos no fijos: una figura en la encrucijada. Bomarzo.

Boltaina Bosch, X. (2005). Empleo precario y conflictos jurídicos en las administraciones públicas locales y autonómicas. Cuadernos Constitucionales de la Cátedra Fadrique Furió Ceriol, 52-53, 185-219.

Boltaina Bosch, X. (2018). Los procesos selectivos blandos y sus efectos sobre la profesionalización del empleo público. Revista Vasca de Gestión de Personas y Organizaciones Públicas, 2 (núm. extra), 140-155. https://www. euskadi.eus/r61-apprvop/eu/t59auUdaWar/R3/verArticulo?numejem=3\&tipo=S\&seccion=51\&correlativo=1\&conten ido $=8 \&$ locale $=$ es

Boltaina Bosch, X. (2021). El Real Decreto Ley 14/2021 sobre personal interino y estabilización: la compleja aplicación transitoria en la Administración Local. Revista digital CEMCI, 51 (julio-septiembre), 1-30. https://revista.cemci. org/numero-51/pdf/tribuna-1-el-real-decreto-ley-14-2021-sobre-personal-interino-y-estabilizacion-la-complejaaplicacion-transitoria-en-la-administracion-local.pdf

Boltaina Bosch, X. (2021a). El contrato de interinidad por plaza vacante tras la sentencia del Tribunal Supremo de 28 de junio de 2021: consecuencias para la gestión de los recursos humanos en las entidades locales. La Administración práctica, 8, 51-63.

Brufao Curiel, P. (2021). Funcionarios interinos y empleo público: análisis general de su controvertido régimen jurídico. RVAP, 120, 19-60. https://doi.org/10.47623/ivap-rvap.120.2021.01

Cabrera Rodríguez, J. (2020). Función Pública temporal y precario administrativo. Revista Aragonesa de Administración Pública, 55, 392-415.

Campos Daroca, J. M. (2017). Empleo público y fraude en la contratación temporal. Editorial Dykinson.

Cantero Martínez, J. (2017). El funcionario interino en la jurisprudencia: sobre la necesidad de repensar la figura. Revista Vasca de Gestión de Personas y Organizaciones Públicas, 12, 8-29. https://apps.euskadi.eus/z16-a5app2/ es/t59auUdaWar/R3/verArticulo?numejem=12\&tipo=R\&seccion=51\&correlativo=1\&contenido=5\&locale=es

Cantero Martínez, J. (29 de julio de 2021). Los principios constitucionales rectores del empleo público no se negocian: a propósito de los interinos [entrada de blog]. Hay Derecho. https://www.hayderecho.com/2021/07/29/losprincipios-constitucionales-rectores-del-empleo-publico-no-se-negocian-a-proposito-de-los-interinos/

Cantero Martínez, J. y Jiménez Asensio, R. (6 de julio de 2021). La temporalidad enquistada en el empleo público: la temporalidad futura como problema institucional [entrada de blog]. Hay Derecho. https://www.hayderecho. com/2021/07/06/la-temporalidad-enquistada-en-el-empleo-publico-la-temporalidad-futura-como-problemainstitucional/

Catalá, R. y Cortés, O. (2020), Talento público para una Administración tras el corona shock: propuestas para una reforma ineludible. Esade-PWC. https://www.pwc.es/es/publicaciones/tercer-sector/talento-publico-paraadministracion-corona-shock.pdf

34 Un buen ejemplo de este temor, incluso entre aspirantes aprobados con notas muy altas, pero sin méritos por antigüedad, en https://www.elespanol.com/espana/tribunales/20211126/opositora-temo-interino-sin-plaza-concurso-injusto/629187850_0.html; 27-11-2021. 
DA. Nueva Época - N. 8, diciembre 2021 - ISSN: 1989-8983 - DOI: https://doi.org/10.24965/da.i8.11025 - [Págs. 66-91]

Personal temporal en la Administración Pública: soluciones de presente y opciones de futuro

Xavier Boltaina Bosch

Cavas Martínez, F. (2017). El empleo temporal irregular en el sector público. Anales del Derecho, 35(2). https://revistas. um.es/analesderecho/article/view/296931

CC.OO (2021). Propuestas del Área Pública de CC.OO para reducir la temporalidad y para la estabilización del empleo en el sector público (consultado el 16-12-2021). https://fe.ccoo.es/522f7241b1b5a530925b40591dfe33f4000063. pdf

CONSEJO ECONÓMICO Y SOCIAL (2004). La temporalidad en el sector público [informe 3/2004]. CES. http://www. ces.es/documents/INF/2004/03

DEFENSOR DEL PUEBLO (2003). Funcionarios interinos y personal eventual: la provisionalidad y temporalidad en el empleo público [Informe]. Recuperado de https://www.defensordelpueblo.es/informe-monografico/funcionariosinterinos-y-personal-eventual-la-provisionalidad-y-temporalidad-en-el-empleo-publico-2003/

Desdentado Bonete, A. (2018). Los indefinidos no fijos: una historia interminable o una historia terminada. Información laboral, 10, 17-45.

Fondevila Antolín, J. (2018). Problemas y soluciones al Empleo Público actual. Una valoración a los 10 años de la aprobación del EBEP. CEMCI-Diputación de Granada.

Fondevila Antolín, J. (2020). Los claroscuros del EBEP en los procedimientos de concurrencia competitiva: reflexiones empíricas y propuestas innovadoras. Documentación Administrativa, 7, 63-87. https://doi.org/10.24965/ da.i7.10898

Fuentetaja Pastor, J. (2019). En cuanto sea adecuado a la naturaleza de su condición: la convergencia de régimen jurídico entre funcionarios de carrera y funcionarios interinos. REGAP, 1(58), 5-27. https://doi.org/10.36402/regap. v1i58.49

Jiménez Asensio, R. (2018). Repensar la selección de empleados públicos. Momento actual y retos de futuro. Revista Vasca de Gestión de Personas y Organizaciones Públicas, 2 (núm. extra), 8-29. https://apps.euskadi.eus/z16a5app2/es/t59auUdaWar/R3/verArticulo? numejem=3\&tipo=S\&seccion=60\&correlativo=1\&contenido=1\&locale=es

Jiménez Asensio, R. (10 y 11 de abril 2019). Doce tesis y seis hipótesis sobre la selección de empleados públicos y su futuro [Ponencia]. Jornadas sobre los procesos selectivos en la Administración Pública en la Unión Europea, nuevos planteamientos para nuestro tiempo. IVAP/EIPA. https://rafaeljimenezasensio.files.wordpress. com/2019/04.

Jiménez Asensio, R. (24 de noviembre de 2021). Proyecto de ley de medidas urgentes de reducción de la temporalidad en el empleo público [Documentos]. La mirada institucional. https://rafaeljimenezasensio.files. wordpress.com/2021/11/proyecto-de-ley-de-medidas-urgentes-de-reduccion-de-la-temporalidad-en-el-empleopublico121-63_dictamen-2.pdf

López Ramón, F. (2021). Miguel Sánchez Morón, Régimen Jurídico de los funcionarios interinos [Recensión de monografía]. RAP, 214, 373-374. https://recyt.fecyt.es/index.php/RAP/article/view/88962

Mateos Martínez, J. (2020). El derecho a la no discriminación de los funcionarios interinos. RVAP, 117, 387-419. https:// doi.org/10.47623/ivap-rvap.117.2020.09

Ramió, C. (11 de julio de 2017). Una Administración pública obsoleta. El País. https://elpais.com/elpais/2017/07/08/ opinion/1499529337 276630.html

Rojo Torrecilla, E. (2021). Empleo Público. Notas previas y texto comparado del proyecto de Ley, del Informe de la ponencia y del texto aprobado por la Comisión de Hacienda y Función pública de 22 de noviembre de 2021. http:// www.eduardorojotorrecilla.es/2021/11/empleo-publico-notas-previas-y-texto_25.html

Rojo Torrecilla, E. (23 de diciembre de 2019). Tres propuestas para el nuevo empleo público. El blog de espublico. https://www.administracionpublica.com/tres-propuestas-para-el-nuevo-empleo-publico/

SINDICATO ANDALUZ DE FUNCIONARIOS - SAF (25 de noviembre de 2021). Informe sobre la inconstitucionalidad de la ley de medidas de reducción de la temporalidad.

Sánchez Morón, M. (2019). La consagración del funcionario interino indefinido. RAP, 208, 223-238. https://doi. org/10.18042/cepc/rap.208.06

Sánchez Morón, M. (2020). Régimen jurídico de los funcionarios interinos. Thomson Reuters Aranzadi.

Sánchez Trigueros, C. (2017). Incidencia de la reciente doctrinal del TJUE sobre temporalidad en el empleo público. Anales de Derecho, 35(2). https://revistas.um.es/analesderecho/article/view/275521 